Research Article

\title{
Fragility Comprehensive Assessment of Low-Rise Cold-Formed Steel Framed Wall Structure Subjected to Wind Load
}

\author{
Hao Zhang $\mathbb{D}^{1},{ }^{1}$ Shiwei Hou $\mathbb{D}^{1},{ }^{1}$ Yiming Ding, ${ }^{1}$ Chao $\mathrm{Li}^{2}{ }^{2}$ and Pengfei Liu ${ }^{1}$ \\ ${ }^{1}$ School of Civil Engineering, Shenyang Jianzhu University, Shenyang 110168, China \\ ${ }^{2}$ Faculty of Infrastructure Engineering, Dalian University of Technology, Dalian 116024, China \\ Correspondence should be addressed to Shiwei Hou; houshiwei@sjzu.edu.cn
}

Received 18 June 2021; Revised 21 July 2021; Accepted 8 August 2021; Published 19 August 2021

Academic Editor: Piguang Wang

Copyright (c) 2021 Hao Zhang et al. This is an open access article distributed under the Creative Commons Attribution License, which permits unrestricted use, distribution, and reproduction in any medium, provided the original work is properly cited.

This paper presents a comprehensive assessment method of the fragility of low-rise cold-formed steel (CFS) framed wall structures subjected to wind hazards considering the fragility of both the main structure and the cladding system. The effects of wind directions on the fragility of CFS framed wall structures were also studied. For the main structure, the fragility curve is established using the maximum interstory drift ratio $\left(\mathrm{ISDR}_{\max }\right)$ as the performance index for assessing the wind fragility of the structure. For the cladding system, the probabilistic models of the wind load and the cladding component resistance are established based on Monte Carlo simulation, and then methods for the fragility assessment of single cladding components and the cladding system under wind hazards considering the influence of the number and arrangement of the cladding components are proposed. The results indicated that, under strong wind, the cladding system may be damaged before the required wind resistance capacity of the main structure is exhausted. In particular, the roof sheathing is the most prone to damage, followed by the stud wall. That is, before the main structure is severely damaged or collapses, the cladding systems may be severely damaged, rendering the structure unusable. Therefore, the comprehensive assessment of the fragility of this type of structure subjected to wind hazard considering the fragility of both the main structure and the cladding system is more accurate. This study is of great significance for the improvement of the wind resistance performance of CFS structures and the popularization of this type of structure.

\section{Introduction}

Low-rise cold-formed steel (CFS) framed wall structures evolved from wood-frame structures and are mostly used in low-rise residential buildings. With the scarcity and rising cost of timber resources as well as the increasing demands for environmental protection, this type of structure has been widely used as a substitute for timber structures in many developed countries and regions such as the United States, Japan, and Australia. CFS framed wall structures offer a multitude of advantages; for example, they are lightweight, have high strength, high construction efficiency, elegant structural form, and a high degree of industrialization, use less energy, and are environmentally friendly [1]. Wind is a common natural hazard that impacts high-rise structures, long-span structures, and lightweight low-rise structures, causing various degrees of structural damage or even collapse. As an important component of the performancebased wind design of structures, wind fragility analysis quantifies the probability of a structure or its components exceeding a certain failure limit state under different hazard intensities [2]. In recent years, a large number of studies have been carried out on the fragility of structures subjected to wind hazards [3]. Ellingwood et al. [4-8] proposed a modified statistical parameter model for wind loads and a performance-based fragility analysis method for woodframe structures; they conducted multi-hazard fragility analysis and risk assessment of lightweight wood-frame structures considering the effects of multiple hazards such as earthquakes and strong winds. Lee and Rosowsky [9] established the fragility curves of wood-frame structures under combined snow and earthquake loads based on nonlinear dynamic time-history analysis and probabilistic demand analysis and studied the effects of snow loads on the 
seismic fragility of wood-frame structures. It was concluded that a snow load significantly increases the vertical load of a structure and thus increases the failure probability of the structure under earthquake. van de Lindt and Dao [10] proposed performance objectives for wood-frame structures under strong winds, provided wind fragility analysis methods for various main components using the proposed performance objectives, and studied the wind fragility of a wood-frame building as an example. Fu et al. [11] developed a method for the wind fragility analysis of a transmission tower-line system by incorporating the uncertainties of structural parameters and wind loads in the numerical analysis model and then carried out a wind fragility analysis of the system using the proposed method. Asareh et al. [12] investigated the fragility of wind turbines under combined earthquake and wind. The results showed that an increase in the wind speed increases the probability of exceeding different damage limit states of the structure and that the wind load had less influence on the fragility of the structure than the seismic load.

Low-rise CFS framed wall structures mainly consist of two parts-the cold-formed steel wall frame and the cladding system, as shown in Figure 1. The wall is a ribbed slab system composed of section steel studs, wall tracks, and sheathed with oriented strand boards (OSB) or gypsum boards, etc.; it relies on its in-plane stiffness to resist horizontal loads such as wind and earthquakes [13]. The floor is mainly composed of joists, floor tracks, and slabs, etc. Once the main structure is damaged, not only is safety not guaranteed, but also enormous property losses can occur. Therefore, the performance of the main structure largely determines the safety of this type of structure. Currently, structural and component model tests and numerical simulations are the main means for studying the disaster resistance performance of CFS framed wall structures. Fueloep and Dubina [14, 15] carried out load-bearing tests and numerical simulations of CFS walls under monotonic and cyclic loadings; they developed a restoring force model for this type of wall based on test and numerical analysis results and used the proposed restoring force model to conduct nonlinear dynamic time-history analysis of the CFS framed structure. Selvaraj and Madhavan [16] studied the requirements of the sheathing CFS framed walls to inhibit the lateral torsional buckling (LTB) of the hat-shaped CFS member subjected to out-of-plane loading through experiments and described the need for explicit minimum sheathing requirement provisions for different geometries of CFS structural members which are currently absent in the present design specifications. Li et al. [17] carried out loadbearing tests on various main components of a CFS framed wall structure and provided practical methods for the design of these components; finally, they conducted full-scale shaking table tests to investigate the seismic response of the structure as well as the failure modes of the connections and components and proposed a method for the seismic design of CFS framed wall structures, which was later adopted in the revision of the Chinese code Technical Specification for LowRise Cold-Formed Thin-Walled Steel Buildings (JGJ 2272011) [18]. Jiang and Ye [19] conducted seismic risk analysis

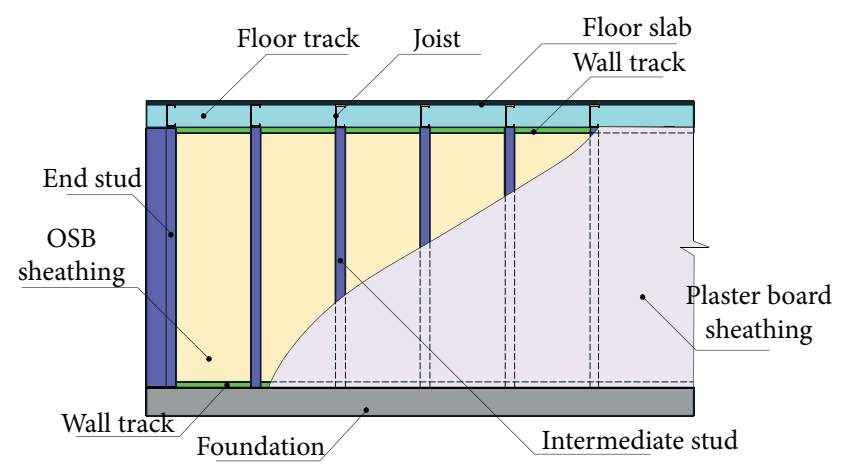

FIgURE 1: The schematic of low-rise CFS framed wall structural system.

on the 2-story steel sheathed CFS structure based on the seismic vulnerability analysis results, and the influence of four types of uncertainties was considered in the analysis process.

The cladding system of the CFS structure mainly includes stud wall and roof sheathings. Once the cladding system is damaged, the structure will not be usable and needs to be promptly repaired. The CFS framing walls are not only part of the main structure but also an important cladding component. When the walls are considered as a cladding component, their out-of-plane load-bearing performance is of primary concern [20,21]. The roof sheathing consists of roof trusses, purlins, and roof panels, with the roof panels and purlins typically bolted together. When a wind load acts on the structure, the airflow creates a vortex at the surface of the roof stud wall panels, resulting in a wind pressure on the roof and the windward and leeward walls $[22,23]$. The magnitude and distribution of the wind pressure are affected by a multitude of factors such as the building plan dimensions, roofing type, roof pitch, and wind direction, as well as the surrounding buildings and topography [24-27]. The roof panels are generally made of lightweight, highly flexible sheet material. For example, the roof panels are usually composed of profiled steel sheets with a thickness of $0.4-1.6 \mathrm{~mm}$, and the wall sheathing panels are generally made of OSBs or gypsum boards, with an out-of-plane stiffness much smaller than the in-plane stiffness. In addition, the main cladding components such as roof panels and wall panels are typically bolted to the CFS frame. Therefore, the cladding members may be the weak part of this type of structure when resisting a high wind load. The results from previous wind disaster investigations have shown that, despite the low probability of low-rise buildings collapsing under strong winds, the cladding components and systems are highly susceptible to severe damage even though the main framing structure remains safe, resulting in the loss of functionality of the structure [28]. For this reason, the research on the wind performance of low-rise buildings has recently focused on cladding components such as the roof and wall sheathings, etc. Lee and Rosowsky [29] developed a fragility model for roof sheathing under wind load considering uplift (suction) based on the results of load-bearing tests on the roof connections for cladding components in lightweight wood-frame construction; they also proposed a 
method for the wind fragility analysis of the roofing system of a wood structure. Rosowsky and Cheng [30, 31] comparatively analyzed the roof wind loads calculated using the recommendations of different codes, statistically studied the historical wind speed records of three coastal areas, and obtained the means and coefficients of variation of wind loads for each area through numerical simulation; then, they studied the reliability of a typical light wood-frame structure using the damage limit states of the structure defined in terms of the extent of loss of the roof sheathing and the condition of roof-to-wall connections. Hassan et al. [32] defined the damage limit states of a structure based on the different conditions of the connections between the cladding components and the main framing structure and conducted wind fragility analysis on five types of wood-frame structures commonly used in the United States, considering multiple combinations of cladding components.

In summary, most of the studies on the wind resistance of low-rise CFS framed wall structures involve cladding components as their research object, and there is a relative lack of studies that comprehensively consider the wind performance of different cladding components and the overall structure. In addition, since the cladding system of a structure is composed of a variety of components, the number and arrangement of the components as well as the wind direction can affect the wind resistance of the structure. Therefore, the evaluation of the fragility of only a kind of single cladding component is not enough for accurate assessment of the wind resistance of the cladding system or even the whole structure. Therefore, in the present study, considering both the safety and serviceability of a CFS structural system subjected to wind hazards, methods for the fragility analysis of the main structure, cladding components, and cladding system are proposed, preliminarily taking into account the influence of the wind direction. According to the results from the nonlinear response analysis of the main structure subjected to a fluctuating wind using a three-dimensional (3D) finite element model, a probabilistic demand model based on displacement demand is established to study the wind fragility of the main structure. In addition, finite element models of two typical cladding components, roof panels, and stud wall panels are developed, and probabilistic models of the wind pressure and cladding component resistance are established. The fragility of each cladding component is obtained by calculating its failure probabilities at different wind speed levels by Monte Carlo simulation (MCS). Based on the results of the fragility analysis of the roof panels and stud wall panels and considering the number and arrangement of different cladding components in the structural system, different damage limit states for the cladding system are defined, and then the fragility curve of the cladding system is constructed by means of independent repeated experiments. Finally, the fragility of this type of structural system subjected to wind hazard is comprehensively assessed based on the results of the fragility analysis of the main structures and the cladding system. The present study is of great theoretical significance for improving the wind-resistant design and performance of CFS structures.

\section{Fragility Analysis Method}

2.1. Method for the Main Structure. The wind fragility of the main structure is defined as the conditional probability of the structure reaching or exceeding a particular limit state under wind of a given intensity:

$$
F_{R}(\varphi)=P[D \geq C \mid \mathrm{IM}=\varphi],
$$

where IM is the wind hazard intensity measure, $D$ is the wind hazard demand, and $C$ is the wind resistance capacity of the main structure.

The fluctuating wind load is first constructed according to different levels of wind load intensity. Then, a 3D finite element model of the CFS framed wall structure is established and subjected to nonlinear dynamic timehistory analysis, and the results of the wind-induced response of the structure under different working conditions are statistically analyzed. The probabilistic wind hazard demand model is established using the 10-minute mean wind speed as the wind hazard intensity measure (IM) and the maximum interstory drift ratio (ISDR) as the engineering demand parameter (EDP), and then the different damage states of the structure are described. The limit states (LS) corresponding to different damage levels of the structure are defined using the maximum ISDR as the performance index, and the exceedance probabilities of the structure at different LS are calculated to generate the fragility curve.

\subsection{Methods for the Cladding Component and System.} The cladding system of the CFS framed wall structure mainly includes the roofing system and the stud wall system, which contain a large number of components and connections. The relevant parameters are highly uncertain, so it is impossible to rapidly establish the probabilistic demand model by directly using the objective function in the fragility analysis of the main structure as described above, making it difficult to implement the fragility analysis of the cladding system. MCS [33] is independent of the specific types of probability distributions of the variables and can take parameter uncertainties into account. An approximate solution for the fragility can be obtained through experimentation and statistical analysis on a large number of random samples. In this paper, a component-level-based analysis method is proposed to study the fragility of the cladding system. The fragilities of two types of main cladding components (roof panel and stud wall) are first calculated separately using MCS, and then the fragility of the cladding system of the structure is assessed based on the fragility analysis results of different types of cladding components [34].

2.2.1. Cladding Component. For each type of cladding component, the probabilistic models of wind load and cladding component resistance are first established, based on which the wind load effect and the cladding component resistance are statistically analyzed by MCS using the following performance function: 


$$
Z=R-S
$$

where $R$ is the cladding component resistance and $S$ is the effect of random wind load on the cladding components. $Z<0$ indicates the failure of the cladding component.

First, the fragility of a single cladding component is calculated by MCS. That is, at a given wind speed level, the analysis of a certain type of cladding component is carried out $M$ times, and the number of component failures, $M_{i}$, is counted. The failure probability of the cladding component, $P$, is calculated using the following equation:

$$
P=\frac{M_{i}}{M}
$$

where $P$ is the failure probability of the cladding component, $M_{i}$ is the number of cladding components reaching a failure state, and $M$ is the total number of analyses.

The fragility of the cladding component can be obtained through a series of statistical analyses on the calculation results corresponding to different wind speed levels. For the roof panel, considering the uncertainty of the gravity load, negative wind pressure is applied to the roof panel based on a probabilistic wind load model. In addition, the force at the connection joint between the roof panel and the purlin is calculated by setting the connection as a hinge. The resistance of the joint is then randomly generated using the probabilistic model of the roof panel resistance. The connection is considered to fail when the calculated connection force exceeds the generated resistance value. When one of the connection joints of the roof panel fails, the internal force is redistributed among the other connection joints of the panel under wind load, causing the successive failure of these connection joints. Therefore, the failure of a roof panel is defined as the failure of any of its connection joints. For the cladding wall, a random wind pressure generated by the probabilistic wind load model is applied to the cladding wall, and the bending moment at the support of the wall stud is calculated and compared with the resistance randomly generated by the probabilistic cladding wall resistance model. The wall is considered to fail when the calculated bending moment exceeds the resistance. For a single cladding component, the wind load effect under the most unfavorable condition is usually considered, and the obtained fragility analysis result can probabilistically reflect the wind resistance capacity of the single component and its connection joints, providing an important theoretical reference for improving the wind resistance. However, the fragility analysis of a single cladding component is unable to accurately reflect the wind resistance of the whole cladding system of the structure, the fragility of which should be further analyzed on this basis. In the present study, a method for the fragility analysis of the cladding system is proposed based on the fragility analysis results of the cladding components.

2.2.2. Cladding System. The present study considers only the roof panel and the cladding wall as two types of cladding components. Hence, the fragility of the cladding system can be defined as the total probability of different degrees of damage to the roofing system and the cladding wall system under wind loads. The degree of damage to the cladding system of the structure not only depends on the wind resistance of a single cladding component but also is affected by factors such as the number, area, and arrangement of various types of cladding components. In the present study, the fragility of the whole cladding system is assessed using the independent repeated experiment method based on the failure probability of a single component at different wind speed (intensity) levels, considering the number, area, and arrangement of the various types of components of the cladding system and different wind direction inputs. First, the components of the cladding system are classified according to their different load-bearing states under wind load, and then the damage probabilities of the cladding components under different wind speed levels are calculated. Assuming that the damage to each cladding component is independent, the failure state of all the components of the cladding system can be determined based on the damage probability of a single component at a certain wind speed level; the damage ratio of the roofing system or cladding wall system can be calculated using equation (4), and different damage limit states of the roofing system or cladding wall system can be defined to determine the damage state of the roofing system or cladding wall system. On this basis, $N$ independent repeated random experiments are conducted, and the probability $P$ of each damage state of the roofing system or the cladding system is calculated using equation (5). The above calculation process is repeated to analyze the exceedance probability of the roofing system or envelope system for each damage state at different wind speed levels and different wind direction inputs, and thereby, the wind fragility curves of the roofing system and envelope system are obtained.

$$
R_{D}=\frac{A_{D}}{A}
$$

where $R_{D}$ is the damage ratio of a certain type of cladding component and $A_{D}$ and $A$ are the damage area and the total area, respectively, of a certain type of cladding component.

$$
P=\frac{N_{i}}{N},
$$

where $P$ is the exceedance probability of a certain type of cladding system for a damage state, $N_{i}$ is the number of occurrences of slight damage, moderate damage, severe damage, or complete damage, and $N$ is the number of independent repeated random experiments.

\section{Description of the Structural Analysis Model}

A two-story CFS framed wall structure is used as the research object of the present study. The structure has plan dimensions of $9 \mathrm{~m}$ by $7.2 \mathrm{~m}$, a story height of $3 \mathrm{~m}$, and a gable height of $1.8 \mathrm{~m}$, resulting in a total height of $7.8 \mathrm{~m}$. The spacing between adjacent wall studs is $0.6 \mathrm{~m}$, the spacing between floor joists is also $0.6 \mathrm{~m}$, the spacing between the roof trusses in the $x$-axis direction is $1.8 \mathrm{~m}$, and the spacing 
between adjacent two purlins is $0.9 \mathrm{~m}$. The wall frame is sheathed with $12 \mathrm{~mm}$ thick OSB board and $10 \mathrm{~mm}$ thick gypsum board. The detailed dimensions of the structure are shown in Figure 2. The structural frame is mainly composed of $\mathrm{C}$ and $\mathrm{U}$ section steel, as shown in Figure 3. The $\mathrm{C}$ section steel is commonly used for the construction of wall steel stud, joist, and floor truss, and the $\mathrm{U}$ section steel is used for the construction of top and bottom wall track and floor track or used in combination with the $\mathrm{C}$ section steel. The detailed dimensions of the main CFS components are listed in Table 1. It is assumed that the connections between the corner columns and wall tracks are rigid and that all other stud wall track and joist-floor track joints are hinged. The floor live load is taken as $2 \mathrm{kPa}$, and the roof live load is not considered. The roof of the structure consists of 10 roof panels, which are divided according to their locations into two categories, end roof panels (RA) and intermediate roof panels (RB), as shown in Figure 4. The stud wall panels are divided into four categories (WA, WB, WC, and WD) according to their sizes and locations, as shown in Figure 5.

Figure 6 shows the 3D finite element model established using the software ABAQUS. The components of CFS frame such as $\mathrm{U}$ and $\mathrm{C}$ section steels are simulated using B31 beam elements, and the wall panels, floor slabs, and roof panels are all simulated using S4R shell elements. Figure 7 shows the modal analysis results. The natural vibration periods corresponding to the first three vibration modes are $T_{1}=0.21 \mathrm{~s}$, $T_{2}=0.18 \mathrm{~s}$, and $T_{3}=0.13 \mathrm{~s}$. The natural vibration period $T_{1}$ of this type of structure calculated using the equation provided in the Technical Specification for Low-Rise Cold-Formed Thin-Walled Steel Buildings (JGJ227-2011) [18] is in the range of $0.156 \mathrm{~s}$ to $0.234 \mathrm{~s}$, which is basically consistent with the modal analysis result of the finite element model, indicating that the finite element model can reflect the dynamic characteristics of the prototype structure. Rayleigh damping is used in the analysis with a damping ratio of $5 \%$ [35]. A bilinear kinematic hardening model (Figure 8) is used for the skeleton curve of steel, an ideal elastoplastic model (Figure 9) is used for the OSB and gypsum boards, and floor slabs are approximately analyzed by an elastic model. To consider the uncertainty of the structural model parameters in the analysis, parameters such as the steel strength, sectional thickness of the CFS components, wall panel thickness, and roof dead load are taken as uncertain parameters, with their values and probability distributions shown in Table 2. To analyze the fragility of the roof panel and stud wall panels of the cladding system of the structure, finite element models are established for each single roof panel (RA and RB) and stud wall panel (WA, WB, WC, and $\mathrm{WD})$, as shown in Figure 10.

\section{Fluctuating Wind Loads}

To calculate the structural response to wind, considering the randomness of the wind load input and the structural response, the wind load is divided into six 10-minute mean wind speed levels $(20,30,40,50,60$, and $70 \mathrm{~m} / \mathrm{s})$. Using the Davenport spectrum [36] as given in equations (6) and (7), the fluctuating wind speed time history is obtained by equation (8) based on the harmonic superposition method [37]. Four fluctuating wind speed time histories with a time interval $t$ of $0.1 \mathrm{~s}$ are constructed for each 10-minute mean wind speed level. Figure 11 presents the fluctuating wind speed time-history curve for a 10-minute mean wind speed of $40 \mathrm{~m} / \mathrm{s}$. Figure 12 compares the power spectrum corresponding to the time-history curve in Figure 10 with the target Davenport spectrum. The basic consistency between the two spectra indicates that the generated time history can simulate the fluctuating wind well. The fluctuating wind speed time history is superposed with the corresponding 10minute mean wind speed to obtain the calculated wind speed time history acting on the structure using equation (9).

$$
\begin{aligned}
\frac{f S(f)}{v^{2}} & =\frac{4 X^{2}}{\left(1+X^{2}\right)^{4 / 3},} \\
X & =1200 \frac{f}{\bar{v}_{10}},
\end{aligned}
$$

where $S(f)$ is the fluctuating wind speed power spectrum $\left(\mathrm{m}^{2} / \mathrm{s}\right) ; f$ is the frequency $(\mathrm{Hz}) ; \bar{v}_{10}$ is the 10 -minute mean wind speed at $10 \mathrm{~m}$ height $(\mathrm{m} / \mathrm{s})$; and $v$ is the wind speed on the structure, which is taken as $\bar{v}_{10}$ because the model is a low-rise structure with a small number of stories.

$$
v_{i}(t)=\sum_{l=1}^{i} \sum_{k=1}^{N}\left|H_{i l}\left(\omega_{k}\right)\right| \sqrt{2 \Delta \omega} \cos \left[2 \pi \omega_{k} t+\theta_{i l}\left(\omega_{k}\right)+\varphi_{l k}\right] .
$$

In equation (8), $v_{i}$ is the wind speed corresponding to the $i$ th calculating point in the time history; $N$ is the number of frequency sampling points; Hil is the lower triangular matrix of the spectral density matrix after Cholesky decomposition of $S(f) ; \Delta \omega=\left(\omega_{u}-\omega_{l}\right) / N ; \omega_{k}=\omega_{l}+(l-0.5) \Delta \omega$, with $(k=1,2, \ldots, N) ; \theta_{i l}$ is the phase angle of $H_{i l}\left(w_{k}\right)$; the phase angle of $H_{i l}\left(w_{k}\right)$; and $\varphi_{l k}$ is a random value uniformly distributed in the interval $[0,2 \pi]$.

$$
w_{i}=\mu_{s} \frac{1}{2} \rho\left(v_{n}+v_{i}\right)^{2},
$$

where $w_{i}$ is the wind load at the $i$ th calculation point; $\rho$ is the air density, which is taken as $1.2 \mathrm{~kg} / \mathrm{m}^{3} ; v_{n}$ is 10 -minute mean wind speed; $v_{i}$ is the fluctuating wind speed; and $\mu_{s}$ is the wind load shape coefficient, which equals $+0.8,-0.7$, and -0.5 for the windward, crosswind, and leeward sides, respectively, according to the Load Code for the Design of Building Structures (GB 50009-2012) [38].

\section{Wind Fragility Analysis of the Main Structure}

To carry out the wind fragility analysis of the main structure model in Figure 7(b), the 10-minute mean wind speed is selected as the IM of the wind hazard, the ISDR ${ }_{\max }$ is selected as the EDP, and two typical wind directions $\left(0^{\circ}\right.$ and $\left.90^{\circ}\right)$ are considered for the wind load, as shown in Figure 13. It is assumed that the EDP of the wind hazard demand of the main structure is related to the IM of the wind hazard through the following equation [39-41]: 


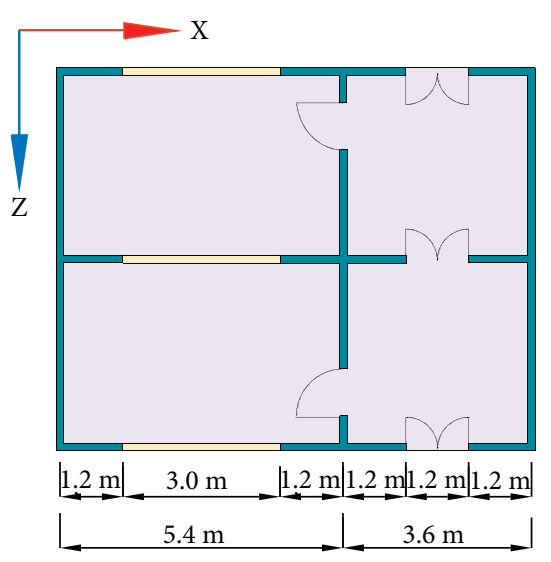

(a)

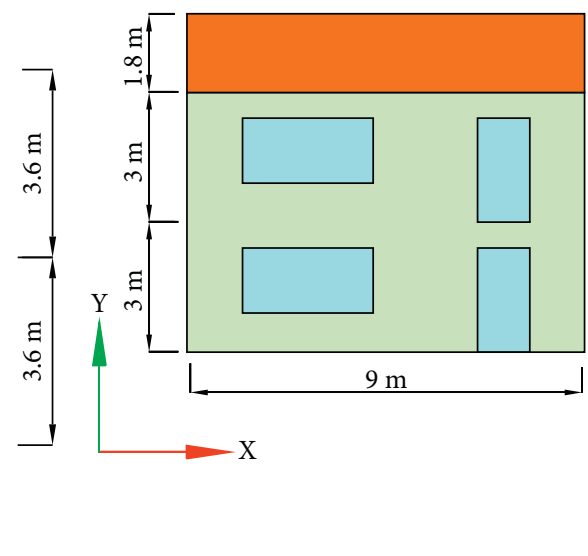

(b)

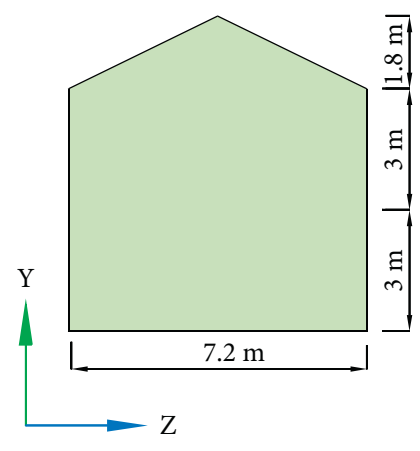

(c)

Figure 2: The plan and elevation views of the structure. (a) Plan. (b) Front elevation. (c) Side elevation.

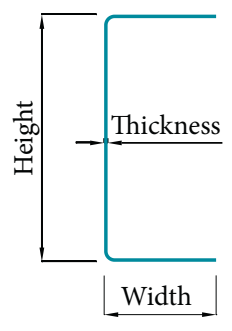

(a)

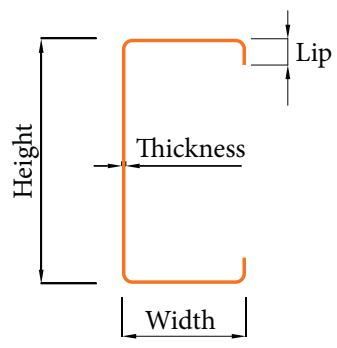

(b)

Figure 3: Sections of CFS. (a) U section. (b) C section.

TABLE 1: Cross-sectional dimensions of the typical CFS components.

\begin{tabular}{lcccccc}
\hline Type & Section & Quantity & Height $(\mathrm{mm})$ & Width $(\mathrm{mm})$ & Thickness $(\mathrm{mm})$ & Lip $(\mathrm{mm})$ \\
\hline Wall track & $\mathrm{U}$ & - & 140 & 40 & 0.9 & N/A \\
Wall studs & $\mathrm{C}$ & - & 140 & 240 & 70 & 12 \\
Floor joist & $\mathrm{C}$ & - & 240 & 70 & 1.2 & 12 \\
Floor track & $\mathrm{U}$ & 2 & & 1.2 & 12 \\
\hline
\end{tabular}

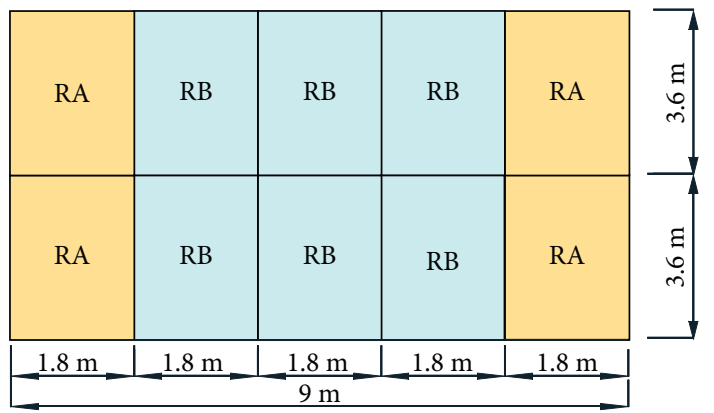

FIgURE 4: Layout of the roofing system.

$$
D=a \mathrm{IM}^{b}
$$

where $D$ is the wind disaster demand parameter (EDP) of the structure, IM is the wind hazard intensity measure, and $a$ and $b$ are regression coefficients.

Taking logarithms on both sides,

$$
\ln D=\ln a+b \ln (\mathrm{IM}) \text {. }
$$

The logarithmic standard deviation can be calculated using the following equation:

$$
\beta_{D \mid I M}=\sqrt{\frac{\sum_{i=1}^{N}\left[\ln \left(D_{i}\right)-\ln \left(a I M^{b}\right)\right]^{2}}{N-2}} .
$$

In equation (12), the smaller the logarithmic standard deviation $\beta_{D \mid \mathrm{IM}}$, the better the fit of the linear regression; $D_{i}$ is the demand of the $i$ th wind hazard, that is, the ISDR $_{\max }$ obtained in the $i$ th time-history analysis of the structure; $N$ is the number of sample points; and $a$ and $b$ are regression coefficients.

The sample set that contains the ISDR $\mathrm{max}_{\max }$ under different wind directions and the corresponding 10-minute mean wind speed $v_{n}$ is obtained through analysis. The data are then regressed to obtain the probabilistic wind hazard demand model (Figure 14 and Table 3). 


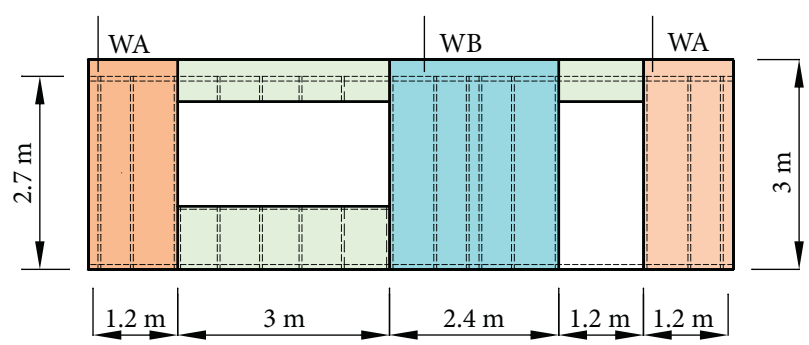

(a)

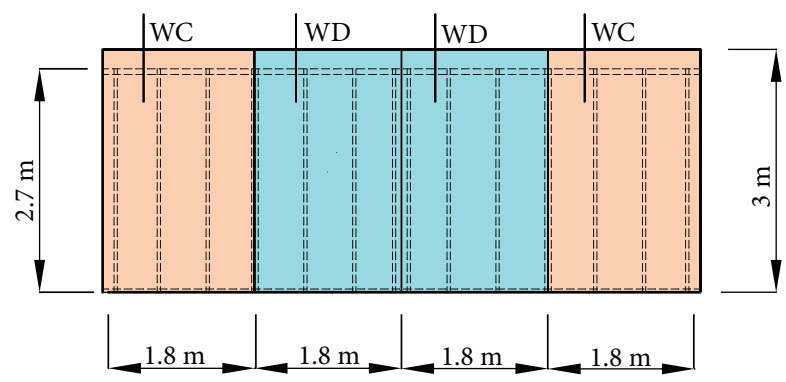

(b)

FIgURE 5: Layout of the cladding wall system. (a) Stud wall panels in $x$-axis direction. (b) Stud wall panels in $z$-axis direction.

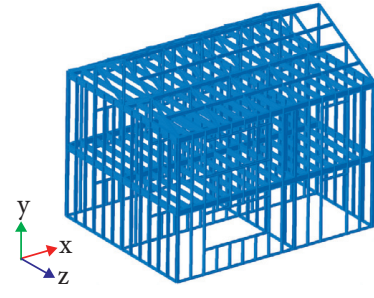

(a)

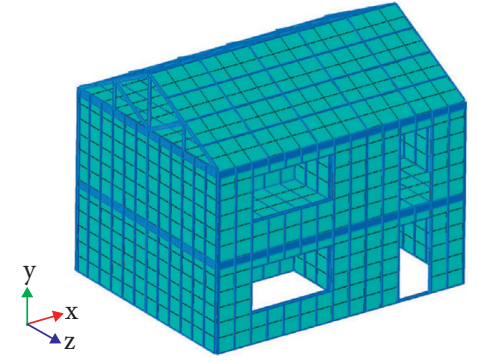

(b)

FIgure 6: The FE model. (a) The CFS frame of the main structure. (b) The main structure sheathed with cladding roof and wall panels.

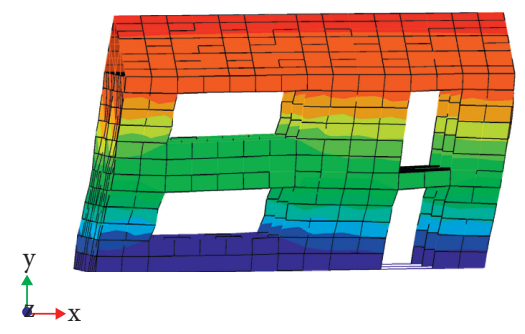

(a)

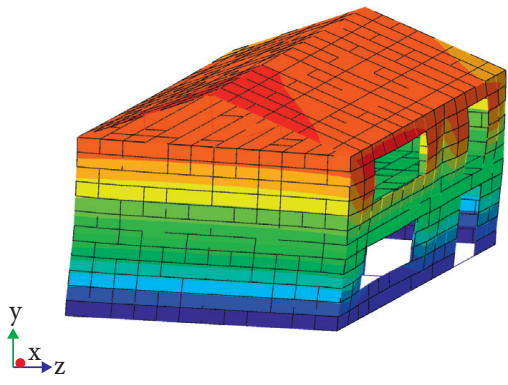

(b)

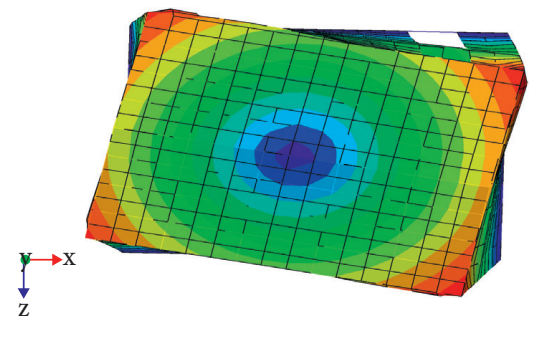

(c)

Figure 7: Results of modal analysis. (a) First vibration mode $\left(T_{1}=0.213 \mathrm{~s}\right)$. (b) Second vibration mode $\left(T_{2}=0.18 \mathrm{~s}\right)$. (c) Third vibration mode $\left(T_{3}=0.13 \mathrm{~s}\right)$.

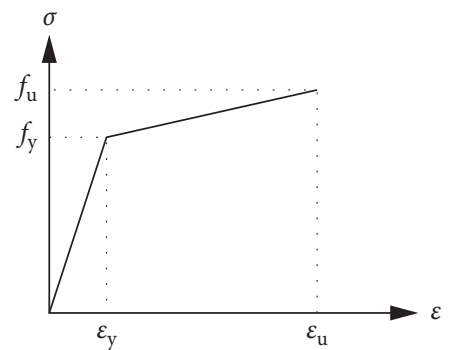

Figure 8: Bilinear kinematic hardening model.

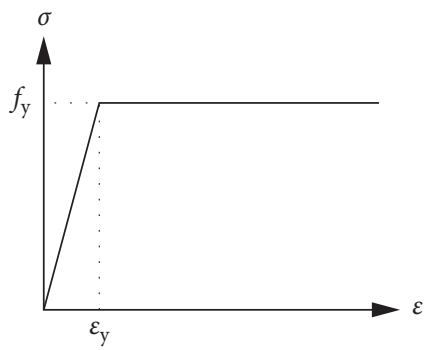

FIGURE 9: Ideal elastoplastic model. 
TABle 2: Probabilistic distribution of the model parameters.

\begin{tabular}{|c|c|c|c|}
\hline Material parameter & Value & Probability distribution & Coefficient of variation (COV) \\
\hline Sectional thickness of CFS components & Nominal value & Normal & 0.035 \\
\hline Wall panel thickness & Nominal value & Normal & 0.035 \\
\hline Yield strength of CFS & $300 \mathrm{MPa}$ & Lognormal & 0.05 \\
\hline Ultimate strength of CFS & $430 \mathrm{MPa}$ & Lognormal & 0.05 \\
\hline Roof dead load & $0.35 \mathrm{kPa}$ & Normal & 0.1 \\
\hline OSB strength & $13 \mathrm{MPa}$ & Normal & 0.05 \\
\hline Gypsum board strength & $4 \mathrm{MPa}$ & Normal & 0.05 \\
\hline
\end{tabular}

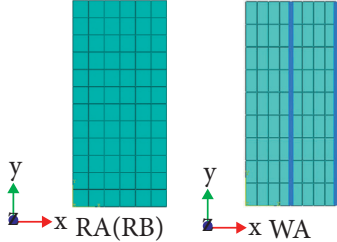

(a)

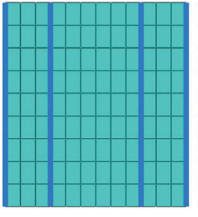

WB

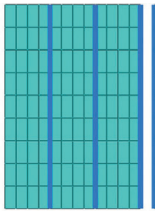

WC

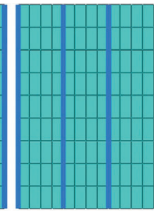

WD

Figure 10: Finite element models of cladding components. (a) Roof panel. (b) Stud wall panels.

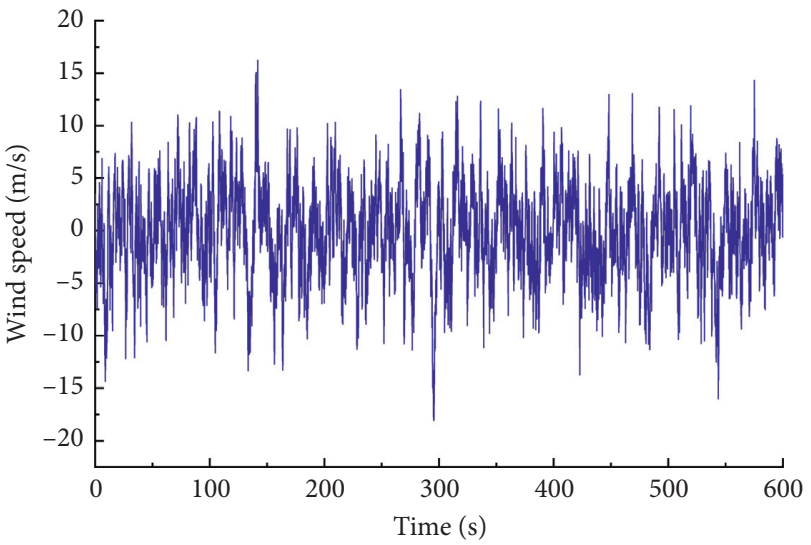

FIGURE 11: Simulated fluctuating wind speed time-history curve $\left(v_{n}=40 \mathrm{~m} / \mathrm{s}\right)$.

The fragility of the main structure follows a normal distribution and can be expressed as follows:

$$
P(D \geq C \mid \mathrm{IM})=\Phi\left[\frac{\ln (\mathrm{EDP})-\ln (\mathrm{LS})}{\sqrt{\beta_{D \mid \mathrm{IM}}^{2}+\beta_{C}^{2}}}\right],
$$

where $\Phi(g)$ is the standard normal distribution function; LS is the performance objective corresponding to each damage limit state of the structure; $\beta_{D \mid I M}$ and $\beta_{C}$ are the standard deviations of the wind hazard demand and wind resistance capacity of the structure, respectively; and $\beta_{C}$ is taken as 0.4 [17].

The wind fragility of the main structure is calculated using equation (14), which is obtained by substituting equation (11) into equation (13).

$$
P(D \geq C \mid \mathrm{IM})=\Phi\left[\frac{\ln (\mathrm{IM})-(\ln (\mathrm{LS})-\ln a) / b}{\left(\sqrt{\beta_{D \mid \mathrm{IM}}^{2}+\beta_{C}^{2}}\right) / b}\right] .
$$

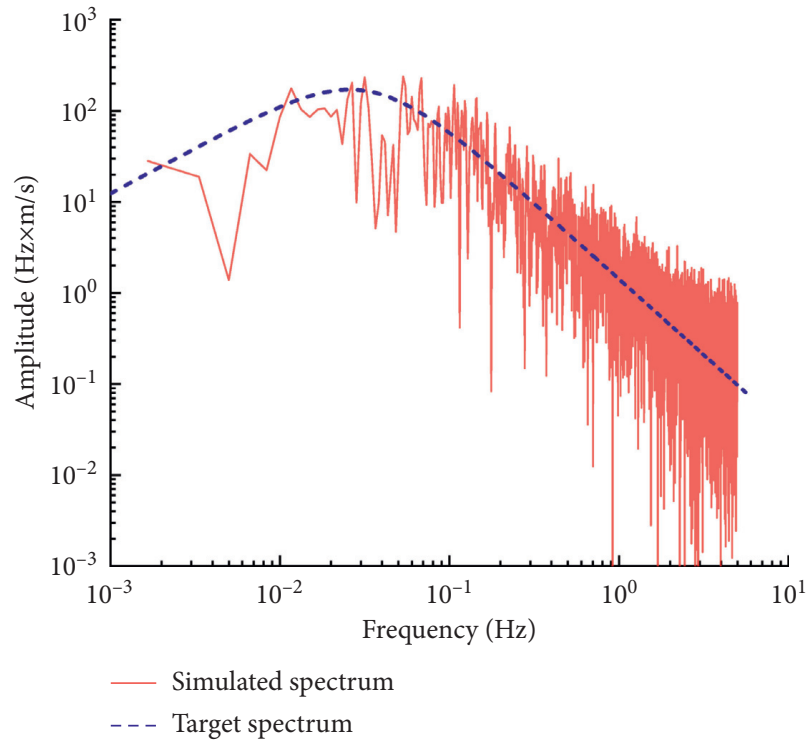

Figure 12: Comparison of simulated and target wind spectra.

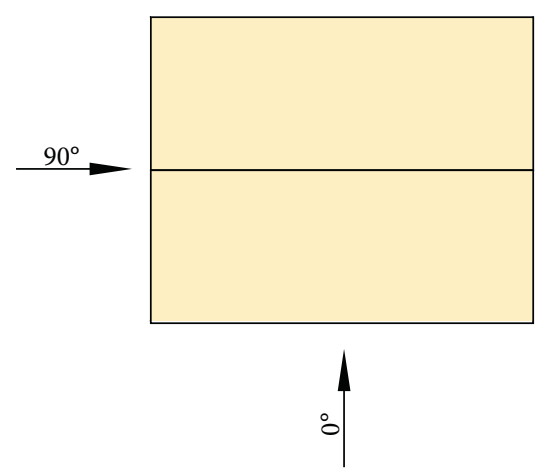

FIgURE 13: Wind direction inputs. 


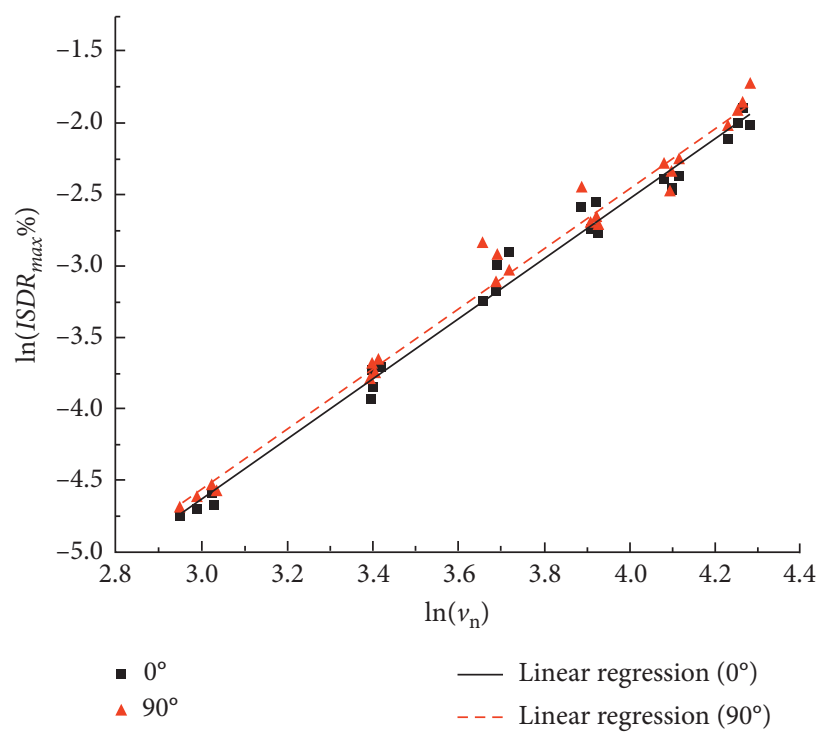

Figure 14: Wind hazard demands of main structure under different wind direction inputs.

TABle 3: Probabilistic wind hazard demand model.

\begin{tabular}{llcc}
\hline Wind direction & Expression of the demand model & Coefficient of determination $R^{2}$ & Standard deviation $\beta_{D \mid \mathrm{IM}}$ \\
\hline $0^{\circ}$ & $\ln \left(\mathrm{ISDR}_{\max }\right)=2.101 \ln \left(v_{n}\right)-10.935$ & 0.988 & 0.100 \\
$90^{\circ}$ & $\ln \left(\mathrm{ISDR}_{\max }\right)=2.114 \ln \left(v_{n}\right)-10.907$ & 0.985 & 0.120 \\
\hline
\end{tabular}

As listed in Table 4, the damage limit states of the main structure are divided as follows [42-44].

Figure 15 shows the wind fragility curves of the main structure. When $v_{n}=50 \mathrm{~m} / \mathrm{s}$, the occurrence probability of "slight damage" is less than $1 \%$; when $v_{n}=70 \mathrm{~m} / \mathrm{s}$ with wind directions of $0^{\circ}$ and $90^{\circ}$, the occurrence probabilities of "slight damage" are $30 \%$ and $37.3 \%$, respectively, and the occurrence probabilities of "moderate damage" are $1.4 \%$ and $2.3 \%$, respectively; when $v_{n}<70 \mathrm{~m} / \mathrm{s}$, the occurrence probability of "severe damage" or "collapse" is very small. Note that the occurrence probability of wind hazards with $v_{n}>70 \mathrm{~m} / \mathrm{s}$ is extremely low in actual situations. For this structure, the occurrence probability of each damage limit state under wind with a direction of $90^{\circ}$ is slightly higher than that with $0^{\circ}$. In addition, the more severe the damage state, the greater the possible effect of the wind direction. The results show that the main structure of a low-rise CFS framed wall structure subjected to wind hazards is mainly dominated by "slight damage" and "moderate damage," while the occurrence probability of "severe damage" or "collapse" is relatively low, and the wind direction has little influence on the wind fragility of the structure.

\section{Wind Fragility Analysis of the Cladding Component and System}

6.1. Wind Load Value on Cladding Components. The wind pressure coefficient recommended by the Metal Building Manufacturers Association (MBMA) in 2006 [45] is used in the present study. The wind pressure on the roof panels and the stud wall panels of the cladding system is determined by the following equation:

$$
w=2.04 \times \frac{1}{2} \rho v_{n}^{2} \mu_{h}\left(\mathrm{GC}_{p}-\mathrm{GC}_{p i}\right),
$$

where $w$ is the wind pressure on the cladding component $(\mathrm{N} /$ $\left.\mathrm{m}^{2}\right) ; \rho$ is the air density, which is taken as $1.2 \mathrm{~kg} / \mathrm{m}^{3} ; v_{n}$ is the 10 -minute mean wind speed at $7.5 \mathrm{~m}$ height with Class $\mathrm{B}$ surface roughness $(\mathrm{m} / \mathrm{s}) ; \mu_{h}$ is the wind pressure height coefficient; and $\mathrm{GC}_{p}$ and $\mathrm{GC}_{p i}$ are the external and internal wind pressure coefficients, respectively.

Since the wind pressure corresponding to $\mathrm{GC}_{p}-\mathrm{GC}_{p i}$ in the MBMA is calculated using the 3 -s gust wind speed while the 10-minute mean wind speed is selected in the present study, a conversion factor of 2.04 is incorporated in equation (15). A total of 11 wind speed levels are set in the range of $20 \mathrm{~m} / \mathrm{s}$ to $70 \mathrm{~m} / \mathrm{s}$ with an increment of $5 \mathrm{~m} / \mathrm{s}$. As shown in Figure 16, the wind pressure coefficient is adjusted for each partitioned zone based on the recommendations in the MBMA 2006; the width $a$ of the edge zones is set to $0.9 \mathrm{~m}$. It is assumed that the wind pressure height coefficient $\mu_{h}$ follows a normal distribution with a mean of 1 [38] and a coefficient of variation (COV) of 0.19 [29]. The roof dead load is also assumed to be normally distributed with a mean of $350 \mathrm{~N} / \mathrm{m}^{2}$ and a COV of 0.1 . The structural model has a gable roof with a pitch of $26.5^{\circ}$, and the effective wind area of the roof panel connector is smaller than $0.93 \mathrm{~m}^{2}$. Table 5 lists the values of $\mathrm{GC}_{p}-\mathrm{GC}_{p i}$ for the different zones in Figure 15.

6.2. Wind Resistance Capacity of the Cladding Components. For a low-rise CFS framed wall structure, negative wind pressure may cause the connection between the roof panel and the purlin to fail, which mainly manifests as one of two 
TABLE 4: Division of the damage limit states.

\begin{tabular}{lcccc}
\hline Damage limit state & Slight damage (LS-1) & Moderate damage (LS-2) & Severe damage (LS-3) & Collapse (LS-4) \\
\hline ISDR $_{\max }$ & $1 / 600$ & $1 / 300$ & $1 / 100$ & $1 / 50$ \\
\hline
\end{tabular}

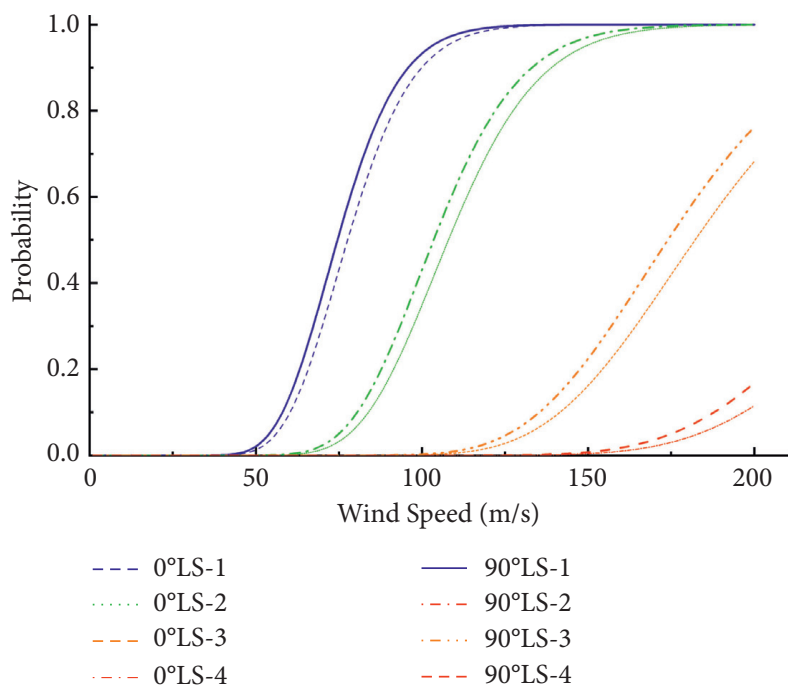

FIGURE 15: Fragility curves of the main structure under horizontal wind loads.

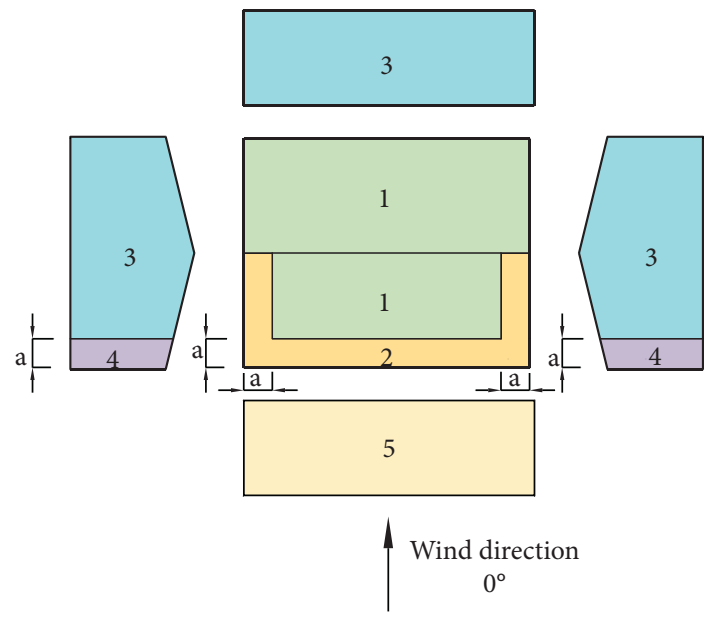

(a)

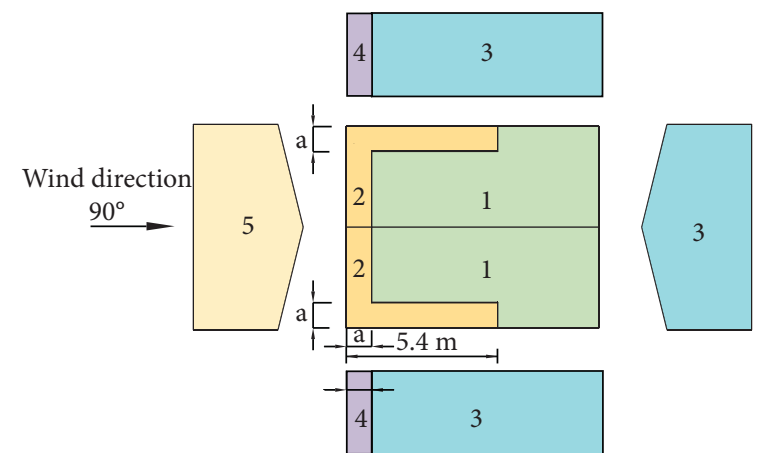

(b)

FIgURE 16: The partition of wind pressure coefficient on the cladding system. (a) Wind direction $\left(0^{\circ}\right)$. (b) Wind direction $\left(90^{\circ}\right)$.

TABLE 5: $\mathrm{GC}_{p}-\mathrm{GC}_{p i}$ values.

\begin{tabular}{lcc}
\hline Partitioned zone & Nominal value of $\left(\mathrm{GC}_{p}-\mathrm{GC}_{p i}\right)$ & $\mathrm{COV}$ \\
\hline 1 & -1.08 & \\
2 & -2.28 & \\
3 & -1.28 & 0.12 \\
4 & -1.58 & \\
5 & +1.18 & \\
\hline
\end{tabular}

failure modes, the detachment of the profiled steel sheets or the pull out of the self-drilling screws in the roof panel, eventually causing the roof panel to fall off. The tensile capacity of a single self-drilling screw can be calculated to assess the load-bearing condition of any connection joint in the roof panel. The bearing capacity of the self-drilling screw corresponding to the above two failure modes is calculated as follows [46]:

$$
N=\min \left\{8.5 t f_{1}, 0.75 t_{c} d f_{2}\right\},
$$

where $N$ is the tensile capacity of a single self-drilling screw; $t$ is the thickness of the profiled steel sheet; $f_{1}$ is the tensile strength of the profiled steel sheet; $t_{c}$ is the penetration depth of the self-drilling screw in the base material; $d$ is the diameter of the self-drilling screw; and $f_{2}$ is the tensile strength of the base material. 
When the wind load acts on the cladding wall, the windward wall is subjected to positive wind pressure, and the leeward wall and two sidewalls are subjected to negative wind pressure. Therefore, the out-of-plane load-bearing performance of the cladding walls is mainly considered. The CFS stud walls can generally be analyzed as flexural members, and an out-of-plane wind load generates bending moments at the upper and lower ends of the wall stud. Here, this bending moment is used as a performance index for evaluating the resistance of the cladding walls to the out-ofplane wind load and is calculated using the following equation:

$$
M=\varphi W f_{3},
$$

where $M$ is the flexural capacity of the end of the wall stud and $\varphi, W$, and $f_{3}$ are the flexural stability coefficient, flexural modulus, and yield strength of the wall stud, respectively.

The relevant parameters of the cladding components all follow a normal distribution, and the mean and COV values of these parameters are shown in Table 6.

\subsection{Fragility Analysis of the Cladding Components.} According to their types, dimensions, and locations, the components of the cladding system are divided into RA and $\mathrm{RB}$, as well as WA, WB, WC, and WD, as shown in Figures 4 and 5. A finite element model is established for each cladding component. The damage probabilities of each component under different wind speed levels are calculated using the MCS method, as listed in Table 7.

Assuming that the fragility of each cladding component under wind load follows the logarithmic cumulative distribution function shown in equation (18), the analysis results obtained under different conditions are fitted to obtain the fragility curve of each cladding component, as shown in Figure 17. Table 8 lists the $m_{R}$ and $\beta_{R}$ values for the fragility curve of each cladding component.

$$
F_{R}(\mathrm{IM})=\Phi\left[\frac{\ln (\mathrm{IM})-\ln \left(m_{R}\right)}{\beta_{R}}\right],
$$

where $F_{R}$ is the fragility of an cladding component; $\Phi(g)$ is the standard normal probability function; IM is the wind load intensity measure; $m_{R}$ is the median of the 10-minute mean wind speed corresponding to the wind resistance capacity of the cladding component; and $\beta_{R}$ is the logarithmic standard deviation of the wind resistance capacity of the cladding component.

Under a wind load, the end roof panel RA are more prone to damage than the intermediate roof panel RB. For example, the failure probabilities of RA and RB under $v_{n}=40 \mathrm{~m} / \mathrm{s}$ are $83.5 \%$ and $26.5 \%$, respectively. For the RA, the damage likely starts to occur when $v_{n}=30 \mathrm{~m} / \mathrm{s}$, and the failure probability begins to increase notably when $v_{n}>35 \mathrm{~m} / \mathrm{s}$ and reaches $100 \%$ when $v_{n}=50 \mathrm{~m} / \mathrm{s}$. For the RB, the failure probability starts to be greater than 0 when $v_{n}=35 \mathrm{~m} / \mathrm{s}$, increases rapidly when $v_{n}>40 \mathrm{~m} / \mathrm{s}$, and is close to $100 \%$ when $v_{n}=55 \mathrm{~m} / \mathrm{s}$. For the cladding walls, the wind resistance performance of the intermediate wall panel WB and WD is higher than that of the end wall panel WA and WC. For instance, the failure probabilities of WA and WB under $v_{n}=60 \mathrm{~m} / \mathrm{s}$ are $53 \%$ and $20.5 \%$, respectively; that is, the failure probability of the WA is $163.4 \%$ higher than that of the WB; the failure probabilities of WC and WD under $v_{n}=60 \mathrm{~m} / \mathrm{s}$ are $39.5 \%$ and $34 \%$, respectively; that is, the failure probability of the WC is $16.2 \%$ higher than that of the WD. Therefore, the cladding components in the edge zones are more susceptible to wind damage than those in the middle zones. In addition, the roof panels have a significantly lower wind resistance capacity than the cladding walls and hence will be damaged sooner. This effect may mainly occur because both the inside and outside of the wall stud are covered with sheet materials and both the top and bottom ends are fixed with wall track, which provide relatively good out-of-plane flexural stiffness and load-bearing capacity. In addition, under the wind load, the airflow is separated from the pediment and the windward eave positions, which generates a higher local negative wind pressure; since the connections between the roof panels and the main structure are provided only by a limited number of self-drilling screws and purlins, the roof panels are more prone to damage than the cladding walls.

6.4. Fragility Analysis of the Cladding System. The fragility analysis of cladding components in the previous section is still not sufficient for assessing the fragility of the whole cladding system in the structure but can provide some theoretical reference. Therefore, to accurately assess the fragility of the whole cladding system, it is necessary to further consider the different values of wind pressure coefficients for various cladding components subjected to wind from different directions. Based on the division of the cladding components in Figures 4 and 5 and the partition of the wind pressure coefficients in Figure 16 and combined with the values of $\left(\mathrm{GC}_{p}-\mathrm{GC}_{p i}\right)$ in Table 6 , the partition of the cladding components is further refined, and the wind pressures of the cladding components based on the new partition are recalculated, as shown in Figure 18. The failure probability of each cladding component under different load conditions is obtained using the MCS. The analysis results are shown in Tables 9 and 10 .

The damage limit states of the cladding system are defined in terms of the damage ratio of the cladding components in the cladding system (i.e., the ratio of the area of a certain type of damaged components to the area of all the components of that type in the cladding system). As shown in Table 11, three damage limit states ("slight," "moderate," and "severe") are defined for the roofing system, and four damage limit states ("slight," "moderate," "severe," and "complete") are defined for the cladding wall system. The fragility of the cladding system is then calculated using the randomly repeated simulation method. In each random simulation under wind at a certain speed level and from a certain wind direction input, assuming that the damage to each cladding component is independent, the failure states of all the cladding components in the cladding system are determined according to their damage probabilities under 
TABLE 6: Parameters of the cladding components.

\begin{tabular}{|c|c|c|c|}
\hline Type & Parameters & Mean value & $\mathrm{COV}$ \\
\hline \multirow{5}{*}{ Roof panel } & Thickness of the profiled steel sheet, $t$ & $0.8 \mathrm{~mm}$ & 0.035 \\
\hline & Yield strength of the profiled steel sheet, $f_{1}$ & $300 \mathrm{MPa}$ & 0.077 \\
\hline & Penetration depth of a self-drilling screw in the base material, $t_{\mathrm{c}}$ & $3 \mathrm{~mm}$ & 0.035 \\
\hline & Diameter of a self-drilling screw, $d$ & $5 \mathrm{~mm}$ & 0.0135 \\
\hline & Yield strength of the base material, $f_{2}$ & $300 \mathrm{MPa}$ & 0.077 \\
\hline \multirow{3}{*}{ Wall panel } & Flexural stability coefficient of the wall stud, $\varphi$ & 0.71 & 0.077 \\
\hline & Flexural section modulus of the wall stud, $W$ & $11000 \mathrm{~mm}^{3}$ & 0.05 \\
\hline & Yield strength of the wall stud, $f_{3}$ & $300 \mathrm{MPa}$ & 0.05 \\
\hline
\end{tabular}

TABLE 7: Damage probabilities of the typical cladding components.

\begin{tabular}{lcccccc}
\hline \multirow{2}{*}{$v_{n}(\mathrm{~m} / \mathrm{s})$} & \multicolumn{6}{c}{ Damage probability (\%) } \\
& RA & RB & WA & WB & WC & WD \\
\hline 20 & 0.00 & 0.00 & 0.00 & 0.00 & 0.00 & 0.00 \\
25 & 0.00 & 0.00 & 0.00 & 0.00 & 0.00 & 0.00 \\
30 & 0.50 & 0.00 & 0.00 & 0.00 & 0.00 & 0.00 \\
35 & 25.0 & 0.50 & 0.00 & 0.00 & 0.00 & 0.00 \\
40 & 83.5 & 26.5 & 0.00 & 0.00 & 0.00 & 0.00 \\
45 & 96.5 & 76.5 & 0.10 & 0.00 & 0.10 & 0.10 \\
50 & 100 & 96.5 & 3.30 & 0.30 & 1.20 & 1.10 \\
55 & 100 & 99.5 & 21.6 & 5.60 & 12.0 & 10.6 \\
60 & 100 & 100 & 54.9 & 21.0 & 38.70 & 33.9 \\
65 & 100 & 100 & 82.9 & 48.5 & 69.0 & 63.3 \\
70 & 100 & 100 & 94.4 & 73.6 & 89.5 & 84 \\
\hline
\end{tabular}

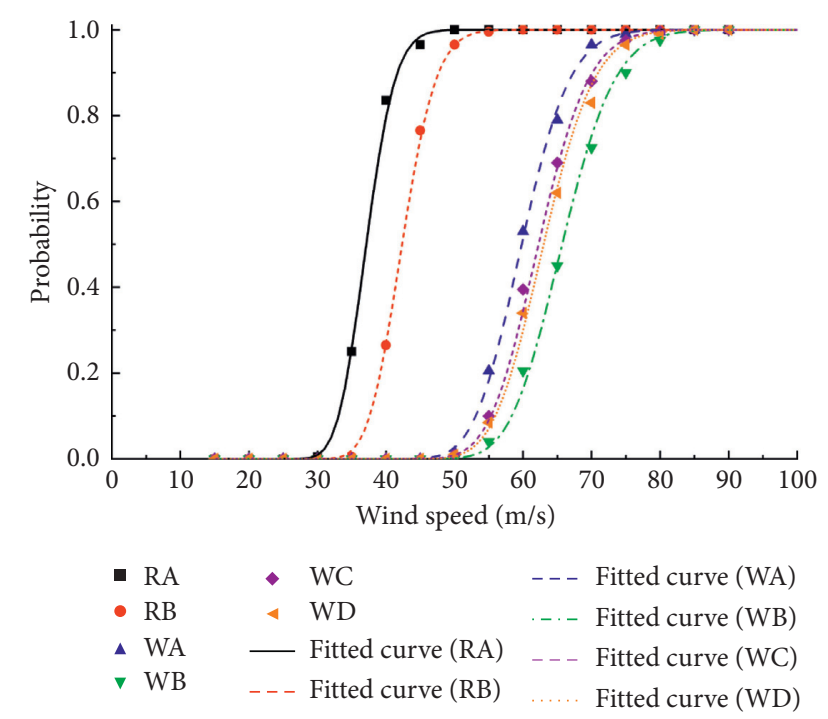

FIGURE 17: Fragility curves of cladding components.

wind at a certain speed level in Tables 9 and 10, and the damage state of the structure is then determined according to Table 11 . The simulation is carried out under 2000 different load conditions, which consider different wind directions and 10-minute mean wind speed levels ranging from $20 \mathrm{~m} / \mathrm{s}$ to $70 \mathrm{~m} / \mathrm{s}$ with an increment of $5 \mathrm{~m} / \mathrm{s}$. The exceedance probabilities of the roofing system or the cladding wall system reaching each damage limit state at different wind speed levels are obtained and then fitted
TABLE 8: $m_{R}$ and $\beta_{\mathrm{R}}$ values for the fragility curves of various cladding components.

\begin{tabular}{lcc}
\hline Cladding components & $m_{R}(\mathrm{~m} / \mathrm{s})$ & $\beta_{R}$ \\
\hline RA & 37.12 & 0.090 \\
RB & 42.35 & 0.093 \\
WA & 59.80 & 0.092 \\
WB & 65.71 & 0.100 \\
WC & 62.26 & 0.096 \\
WD & 63.00 & 0.101 \\
\hline
\end{tabular}

according to equation (18) to obtain the fragility curves of the roofing system and the cladding wall system, as shown in Figures 19 and 20. Table 12 lists the $m_{R}$ and $\beta_{R}$ values of the fragility curves. The wind direction has some effect on the fragilities of the cladding system, but the effect is not significant. For the roofing system under wind with direction angles of $0^{\circ}$ and $90^{\circ}$, the occurrence probabilities of "slight damage" when $v_{n}=35 \mathrm{~m} / \mathrm{s}$ are $41.40 \%$ and $44.90 \%$, respectively; the occurrence probabilities of "moderate damage" when $v_{n}=40 \mathrm{~m} / \mathrm{s}$ are $82.95 \%$ and $87.15 \%$, respectively; and the occurrence probabilities of "severe damage" when $v_{n}=45 \mathrm{~m} / \mathrm{s}$ are $39.50 \%$ and $41.30 \%$, respectively. This is mainly because the damage probability of the single roof panel $\mathrm{RB}_{2}$ is higher than that of $\mathrm{RB}_{1}$ and there are more roof panels $\mathrm{RB}_{2}$ in the wind direction of $90^{\circ}$. For the cladding wall system under the wind with direction angles of $0^{\circ}$ and $90^{\circ}$, the occurrence probabilities of "slight damage" when $v_{n}=50 \mathrm{~m} / \mathrm{s}$ are $13.55 \%$ and $10.95 \%$, respectively; the occurrence probabilities of "moderate damage" when $v_{n}=55 \mathrm{~m} / \mathrm{s}$ are $53.35 \%$ and $58.30 \%$, respectively; the occurrence probabilities of "severe damage" when $v_{n}=60 \mathrm{~m} / \mathrm{s}$ are $35.15 \%$ and $35.05 \%$, respectively; and the occurrence probabilities of "complete damage" when $v_{n}=65 \mathrm{~m} / \mathrm{s}$ are $61.45 \%$ and $63.75 \%$, respectively.

Based on the results of the fragility analysis of the cladding components and the cladding system (Figures 17, 19 , and 20), the wind fragility of the cladding system is different from that of the single cladding components. The case of a wind direction of $0^{\circ}$ is taken as an example. When $v_{n}=35 \mathrm{~m} / \mathrm{s}$, the occurrence probabilities of "slight damage" are $41.4 \%$ for the roofing system and $25 \%$ and $0.5 \%$ for the single edge roof panel RA and the single intermediate roof panel RB, respectively; when $v_{n}=40 \mathrm{~m} / \mathrm{s}$, the occurrence probabilities of "moderate damage" are $83.0 \%$ for the roofing system and $83.5 \%$ and $26.5 \%$ for RA and $\mathrm{RB}$, respectively; 
TABLE 9: Damage probabilities of the roof panels in the roofing system.

\begin{tabular}{lcccc}
\hline$v_{n}(\mathrm{~m} / \mathrm{s})$ & \multicolumn{2}{c}{ Damage probability of the roof panel } \\
& $\mathrm{RA}_{1}$ & $\mathrm{RA}_{2}$ & $\mathrm{RB}_{1}$ & $\mathrm{RB}_{2}$ \\
\hline 20 & 0 & 0 & 0 & 0 \\
25 & 0 & 0 & 0 & 0 \\
30 & 0 & 0.015 & 0 & 0 \\
35 & 0 & 0.25 & 0 & 0.005 \\
40 & 0 & 0.76 & 0 & 0.3 \\
45 & 0.01 & 0.965 & 0.01 & 0.745 \\
50 & 0.145 & 0.995 & 0.145 & 0.965 \\
55 & 0.535 & 1 & 0.535 & 0.995 \\
60 & 0.855 & 1 & 0.855 & 1 \\
65 & 0.98 & 1 & 0.98 & 1 \\
70 & 0.995 & & 0.995 & 1 \\
\hline
\end{tabular}

\begin{tabular}{|l|l|l|l|l|}
\hline $\mathrm{WA}_{3}$ & & $\mathrm{WB}_{3}$ & & $\mathrm{WA}_{3}$ \\
\hline $\mathrm{WA}_{3}$ & & $\mathrm{WB}_{3}$ & & $\mathrm{WA}_{3}$ \\
\hline
\end{tabular}
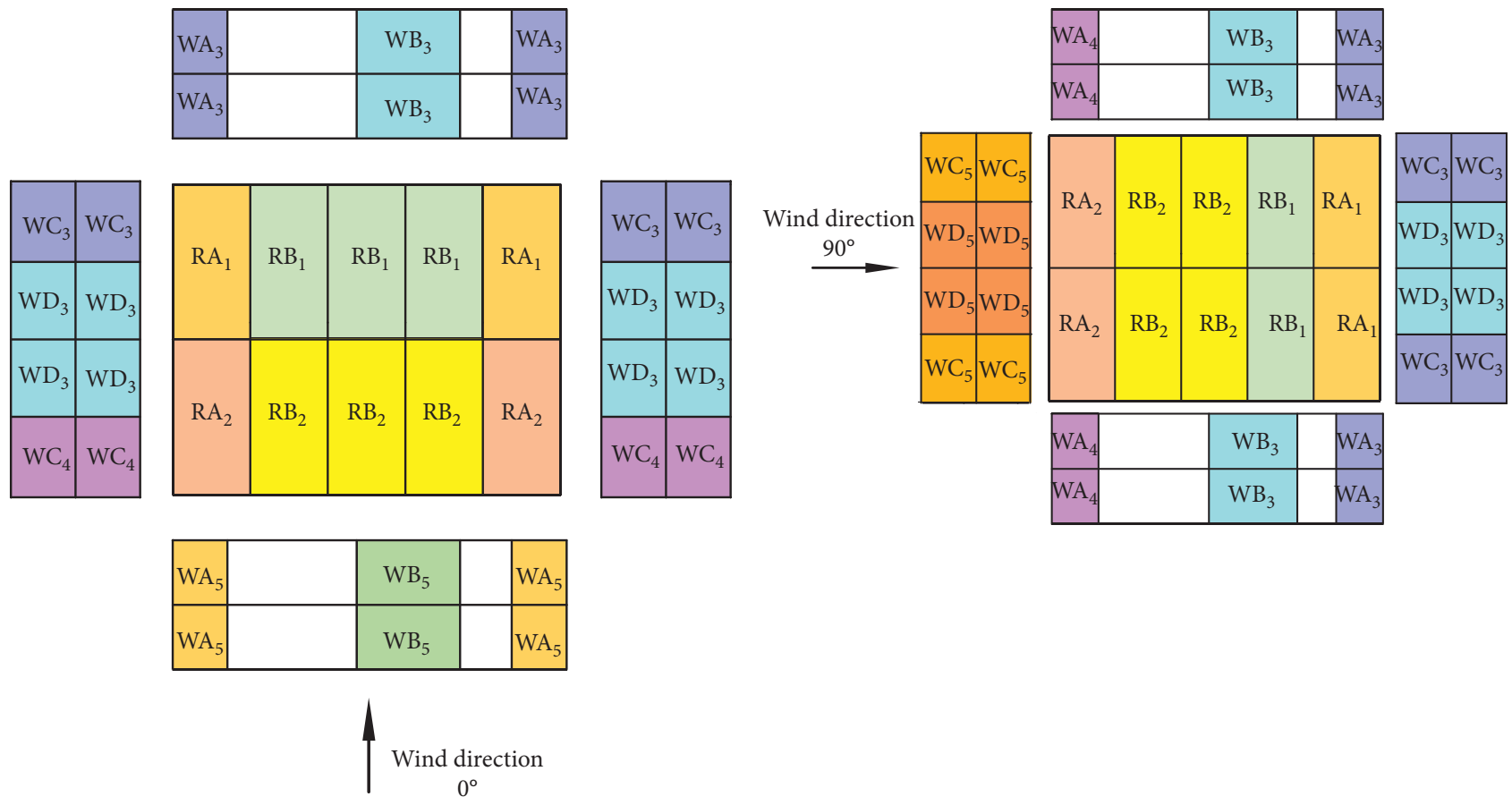

(a)

(b)

FIgURE 18: Partition of cladding components in the fragility analysis of cladding systems. (a) Wind direction $\left(0^{\circ}\right)$. (b) Wind direction $\left(90^{\circ}\right)$.

TABLE 10: Damage probabilities of the cladding wall panels in the cladding wall system.

\begin{tabular}{|c|c|c|c|c|c|c|c|c|c|c|}
\hline \multirow{2}{*}{$v_{n}(\mathrm{~m} / \mathrm{s})$} & \multicolumn{10}{|c|}{ Damage probability of the cladding wall } \\
\hline & $\mathrm{WA}_{3}$ & $\mathrm{WA}_{4}$ & $\mathrm{WA}_{5}$ & $\mathrm{WB}_{3}$ & $\mathrm{WB}_{5}$ & $\mathrm{WC}_{3}$ & $\mathrm{WC}_{4}$ & $\mathrm{WC}_{5}$ & $\mathrm{WD}_{3}$ & $\mathrm{WD}_{5}$ \\
\hline 20 & 0 & 0 & 0 & 0 & 0 & 0 & 0 & 0 & 0 & 0 \\
\hline 25 & 0 & 0 & 0 & 0 & 0 & 0 & 0 & 0 & 0 & 0 \\
\hline 30 & 0 & 0 & 0 & 0 & 0 & 0 & 0 & 0 & 0 & 0 \\
\hline 35 & 0 & 0 & 0 & 0 & 0 & 0 & 0 & 0 & 0 & 0 \\
\hline 40 & 0 & 0 & 0 & 0 & 0 & 0 & 0 & 0 & 0 & 0 \\
\hline 45 & 0 & 0 & 0 & 0 & 0 & 0 & 0 & 0 & 0 & 0 \\
\hline 50 & 0 & 0.015 & 0 & 0 & 0 & 0.005 & 0.010 & 0 & 0.010 & 0 \\
\hline 55 & 0.040 & 0.205 & 0.020 & 0.040 & 0.020 & 0.080 & 0.100 & 0.035 & 0.085 & 0.040 \\
\hline 60 & 0.200 & 0.530 & 0.095 & 0.205 & 0.110 & 0.330 & 0.395 & 0.200 & 0.340 & 0.200 \\
\hline 65 & 0.460 & 0.790 & 0.275 & 0.450 & 0.280 & 0.650 & 0.690 & 0.455 & 0.620 & 0.450 \\
\hline 70 & 0.750 & 0.955 & 0.645 & 0.725 & 0.605 & 0.850 & 0.880 & 0.750 & 0.830 & 0.725 \\
\hline
\end{tabular}


Table 11: Division of the damage limit states of the cladding system.

Damage limit state Damage ratio of the cladding wall system $\left(R_{D, \text { Wall }}\right)(\%)$ Damage ratio of the roofing system $\left(R_{D, \text { Roof }}\right)(\%)$

Slight damage (LS-1)

Moderate damage (LS-2)

Severe damage (LS-3)

Complete damage (LS-4)

$\begin{array}{cc}5 & 20 \\ 15 & 50 \\ 30 & -\end{array}$

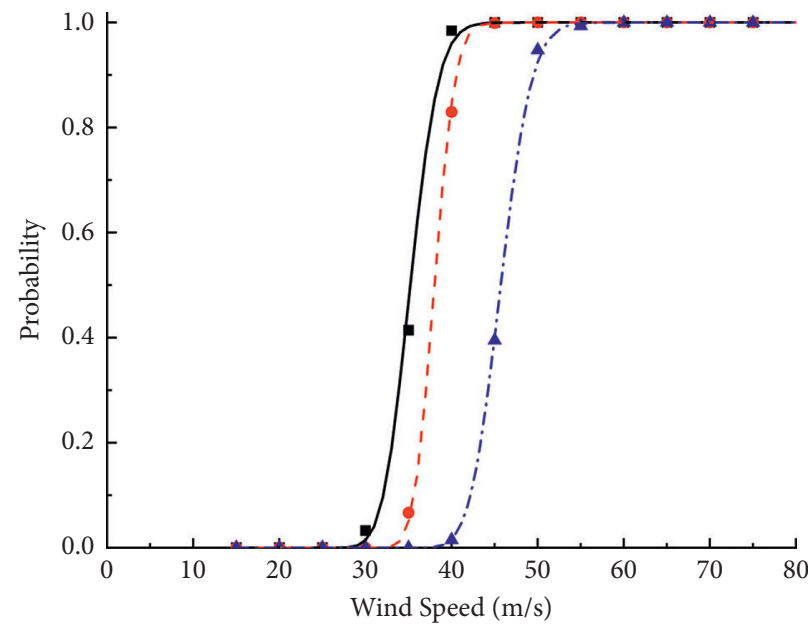

- LS-1

- LS-2

$\Delta$ LS-3

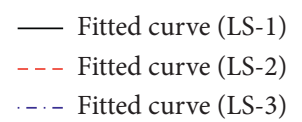

(a)

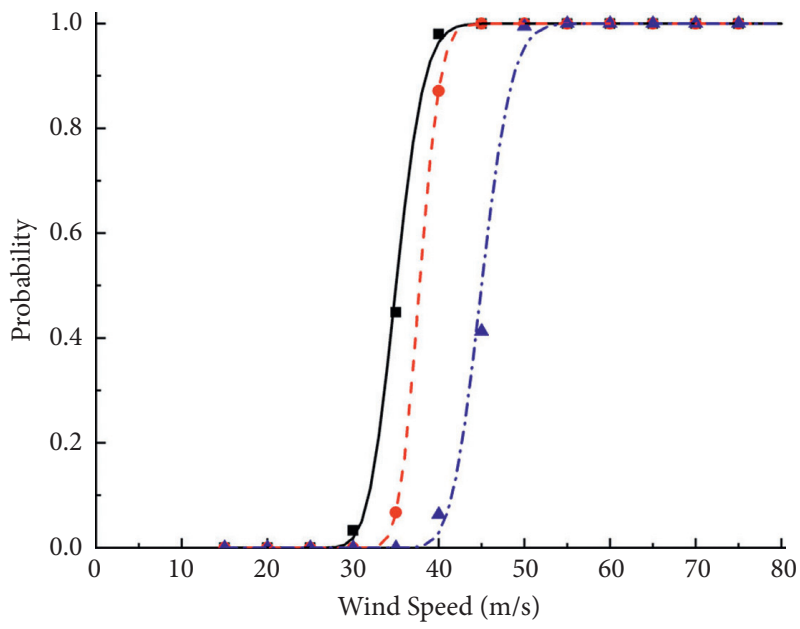

- LS-1

- LS-2

$\Delta$ LS-3

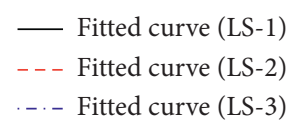

(b)

Figure 19: Fragility curves of the roofing system. (a) Wind direction $\left(0^{\circ}\right)$. (b) Wind direction $\left(90^{\circ}\right)$.
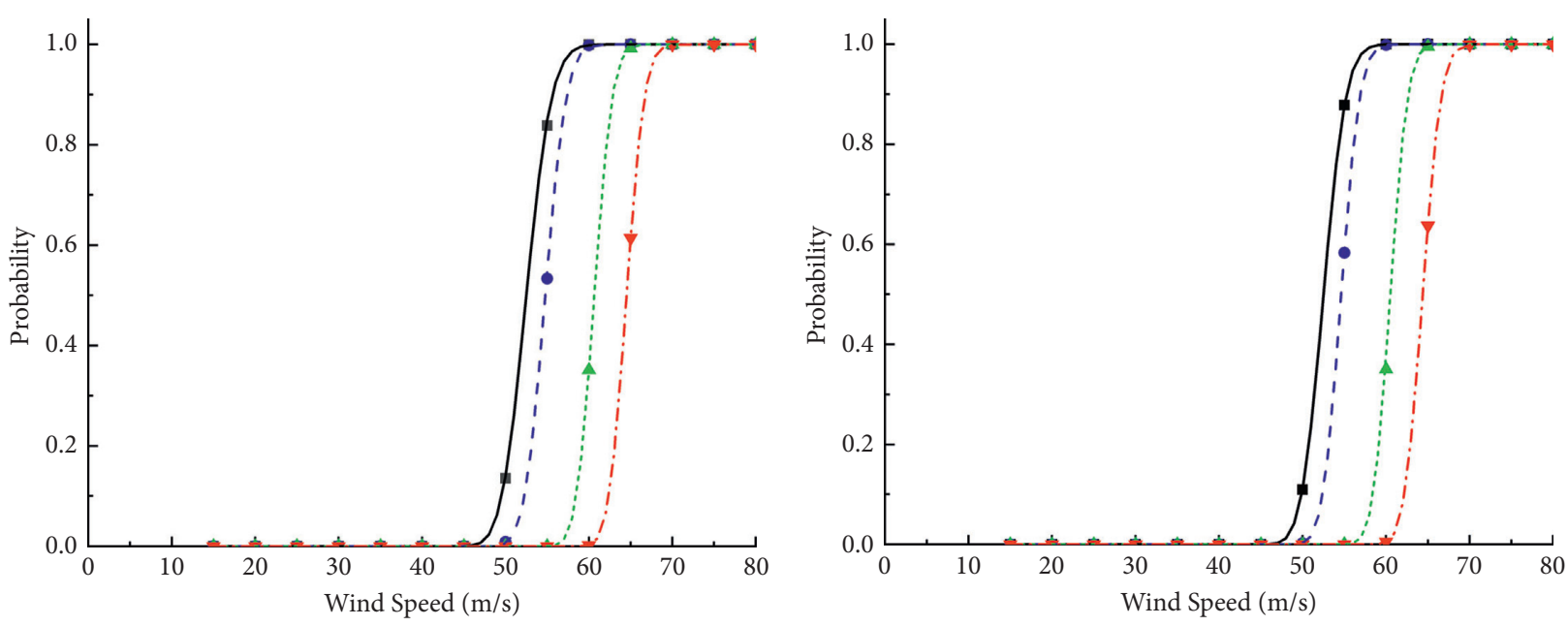

- LS-1

- LS-2

$\triangle$ LS-3

$\checkmark$ LS-4
— Fitted curve (LS-1)

- - - Fitted curve (LS-2)

Fitted curve (LS-3)

_.. Fitted curve (LS-4)

(a)
- LS-1

- LS-2

A LS-3

$\checkmark$ LS-4
- Fitted curve (LS-1)

- - - Fitted curve (LS-2)

Fitted curve (LS-3)

. . . Fitted curve (LS-4)

(b)

FIgURE 20: Fragility curves of the cladding wall system. (a) Wind direction $\left(0^{\circ}\right)$. (b) Wind direction $\left(90^{\circ}\right)$. 
TABLE 12: $m_{R}$ and $\beta_{R}$ values for the fragility curves of the cladding system.

\begin{tabular}{lccc}
\hline \multirow{2}{*}{ Cladding system } & Damage limit & \multicolumn{2}{c}{ Wind direction $/ 0^{\circ}\left(90^{\circ}\right)$} \\
& state & $m_{R}(\mathrm{~m} / \mathrm{s})$ & $\beta_{R}$ \\
\hline \multirow{3}{*}{ Roofing system } & LS-1 & 35.20 & 0.073 \\
& & $(35.00)$ & $(0.074)$ \\
& LS-2 & 38.00 & 0.050 \\
& & $(37.76)$ & $(0.050)$ \\
& LS-3 & 45.70 & 0.062 \\
& \multirow{2}{*}{ LS-1 } & $(45.00)$ & $(0.062)$ \\
\hline & & 52.50 & 0.045 \\
Cladding wall & LS-2 & $52.50)$ & $(0.040)$ \\
system & & $(54.61)$ & 0.036 \\
& LS-3 & 60.64 & $0.032)$ \\
& & $(60.50)$ & $(0.027)$ \\
& LS-4 & 64.51 & 0.026 \\
& & $(64.37)$ & $(0.027)$ \\
\hline
\end{tabular}

and when $v_{n}=45 \mathrm{~m} / \mathrm{s}$, the occurrence probabilities of "severe damage" are $39.5 \%$ for the roofing system and $96.5 \%$ and $76.5 \%$ for RA and RB, respectively; when $v_{n}=50 \mathrm{~m} / \mathrm{s}$, the occurrence probabilities of "slight damage" are $13.6 \%$ for the cladding wall system and $3.3 \%, 0.3 \%, 1.2 \%$, and $1.1 \%$ for single cladding walls $\mathrm{WA}, \mathrm{WB}, \mathrm{WC}$, and $\mathrm{WD}$, respectively; when $v_{n}=55 \mathrm{~m} / \mathrm{s}$, the occurrence probabilities of "moderate damage" are $53.4 \%$ for the cladding wall system and $21.6 \%$, $5.60 \%, 12.0 \%$, and $10.6 \%$ for single cladding walls $\mathrm{WA}, \mathrm{WB}$, $\mathrm{WC}$, and WD, respectively; when $v_{n}=60 \mathrm{~m} / \mathrm{s}$, the occurrence probabilities of "severe damage" are $35.2 \%$ for the cladding wall system and $54.9 \%, 21.0 \%, 38.7 \%$, and $33.9 \%$ for single cladding walls $\mathrm{WA}, \mathrm{WB}, \mathrm{WC}$, and $\mathrm{WD}$, respectively; and when $v_{n}=65 \mathrm{~m} / \mathrm{s}$, the occurrence probabilities of "complete damage" are $61.45 \%$ for the cladding wall system and $82.9 \%$, $48.5 \%, 69 \%$, and $63.3 \%$ for single cladding walls WA, WB, $\mathrm{WC}$, and WD, respectively. Therefore, the use of the fragility of single cladding components alone is insufficient for accurately assessing the degree of damage to the whole cladding system, which necessitates comprehensive consideration of the fragility of single cladding components and cladding system. Under a wind load, the wind resistance capacity of the roofing system is notably lower than that of the cladding wall system. Here, the case of a wind direction of $0^{\circ}$ is taken as an example. When $v_{n}=30 \mathrm{~m} / \mathrm{s}$, the roofing system starts to show "slight damage," while the cladding wall system is intact. When $v_{n}=45 \mathrm{~m} / \mathrm{s}$, the occurrence probability of "moderate damage" in the roofing system is almost $100 \%$, while the cladding wall system is still intact. When $v_{n}=50 \mathrm{~m} / \mathrm{s}$, the occurrence probability of "severe damage" in the roofing system reaches $94.7 \%$, while the cladding wall system just begins to exhibit "slight damage;" and the cladding wall system likely starts to show "severe damage" only when $v_{n}=60 \mathrm{~m} / \mathrm{s}$, which is equivalent to a level 17 super typhoon, with an extremely low occurrence probability.

When the cladding wall system is subjected to wind with $v_{n}>50 \mathrm{~m} / \mathrm{s}$ and directions of $0^{\circ}$ and $90^{\circ}$, the occurrence probabilities of "slight damage" are up to $13.5 \%$ and $11.0 \%$, respectively, and the occurrence probabilities of "moderate damage" are $0.9 \%$ and $0.3 \%$, respectively. In comparison, the main structure likely starts to show "slight damage" when $v_{n}=50 \mathrm{~m} / \mathrm{s}$, and the wind load intensity corresponding to the initial occurrence of slight damage is basically the same for the cladding wall system and the main structure. The roofing system shows significant damage when $v_{n}=30 \mathrm{~m} / \mathrm{s}$, and its damage probability exceeds $95 \%$ when $v_{n}=50 \mathrm{~m} / \mathrm{s}$. In addition, with increasing wind load intensity, the damage probability of the cladding system increases at a markedly higher rate than that of the main structure. When the 10minute mean wind speed increases to $70 \mathrm{~m} / \mathrm{s}$, the occurrence probabilities of "complete damage" to the cladding wall system under the different wind directions reach almost $100 \%$. However, at this time, for the main structure under wind directions of $0^{\circ}$ and $90^{\circ}$, the occurrence probabilities of "slight damage" are $30 \%$ and $37.3 \%$, respectively, the occurrence probabilities of "moderate damage" are $1.4 \%$ and $2.3 \%$, respectively, and "severe damage" or "complete damage" does not occur. This is consistent with the conclusion of a previous wind hazard survey that "under strong wind, low-rise buildings are less likely to collapse while their cladding systems are highly susceptible to damage and loss of function" [26].

\section{Conclusion}

In the present study, the wind fragilities of the main structure and the cladding system of a two-story CFS framed wall structure were separately investigated. The analysis processes and results were presented, and the wind fragility of the structure was comprehensively assessed based on those of the main structure and the cladding system. The main conclusions drawn are as follows:

(1) A composite wall made of a combination of section steel stud and OSB and gypsum board cladding in the structure has satisfactory in-plane stiffness and loadbearing capacity under wind load, resulting in small responses of the main structure to the wind and good wind resistance performance.

(2) For the cladding components, the probabilistic wind load model and resistance model of the cladding component are developed based on component-level analysis, and the wind fragility analyses of the roof panel and cladding wall are performed using Monte Carlo simulation. The results show that the cladding components at the edges are more prone to windinduced damage than those in the intermediate position and that the wind resistance performance of roof panels is markedly lower than that of cladding walls. The fragility of single cladding components differs from that of the corresponding cladding system; the use of the fragility of single cladding components alone is insufficient for assessing the fragility of the whole cladding system.

(3) The analysis of the main structure focuses on the inplane load-bearing performance of the structural components, while the analysis of the cladding 
components and the cladding system mainly emphasizes the out-of-plane load-bearing performance. The results show that the wind load intensity corresponding to the initial occurrence of slight damage to the cladding wall system is almost the same as that to the main structure; the proposed methods for the fragility analysis of the main structure and the cladding system can accurately reflect the damage state of the structure. It is more accurate and reasonable to comprehensively assess the wind resistance capacity of CFS framed wall structures by considering the fragility of both the main structure and the cladding system.

(4) For this type of structure, while the wind resistance capacity of the main structure should be ensured, attention should also be paid to the wind resistance capacity of the cladding components and the cladding system to guarantee the serviceability of the structure. For the roofing system, the load path can be reasonably optimized through design, construction, or reinforcement measures, with special attention given to the load-bearing performance of the connection joints between the roof panels and the structural frame in the edge zones (which can be optimized by, for example, reducing the spacing of the screws and connectors and improving the configuration of the connection joints). Second, the outof-plane load-bearing performance of CFS stud walls should be improved (by, for example, reducing the spacing between the steel studs in the walls or taking appropriate reinforcement measures at the connections between the steel studs and the top and bottom wall tracks) to prevent the instability of the steel studs. It should be noted that two input wind directions are unable to reflect the wind resistance capacity of the CFS framed wall structure accurately. Hence, the wind resistance capacity of this kind of structure under different input wind directions between 0 and 90 should be carried out in future studies, which can ensure the reliable analysis results.

\section{Data Availability}

The datasets presented in this article are not readily available because of embargo reason. Requests to access the datasets should be directed to Hao Zhang (h_zhang@sjzu.edu.cn).

\section{Conflicts of Interest}

The authors declare that there are no conflicts of interest regarding the publication of this study.

\section{Acknowledgments}

The authors would like to acknowledge the financial supports from the National Key R\&D Program of China (2018YFD1100404 and 2016YFC0701108) and the State Key Program of National Natural Science Foundation of China (51738007) for carrying out this research. The supports from the Program of Guangdong Key Laboratory of Earthquake Engineering and Application Technology (2017B030314068) are also gratefully acknowledged.

\section{References}

[1] P. Vitale, A. Spagnuolo, C. Lubritto, and U. Arena, "Environmental performances of residential buildings with a structure in cold formed steel or reinforced concrete," Journal of Cleaner Production, vol. 189, no. 10, pp. 839-852, 2018.

[2] C. O. Unanwa, A model for probable maximum loss in hurricanes, Ph.D. thesis, Texas Tech University, Lubbock, TX, USA, 1997.

[3] G. Pita, J. P. Pinelli, K. Gurley et al., "State of the art of hurricane vulnerability estimation methods: a Review," Natural Hazards Review, vol. 16, no. 2, 2014.

[4] B. R. Ellingwood and P. B. Tekie, "Wind load statistics for probability-based structural design," Journal of Structural Engineering, vol. 125, no. 4, pp. 453-463, 1999.

[5] D. V. Rosowsky and B. R. Ellingwood, "Performance-based engineering of wood frame housing: fragility analysis methodology," Structural Engineer, vol. 128, no. 1, pp. 32-38, 2002.

[6] B. R. Ellingwood and D. V. Rosowsky, Fragility Assessment of Structural Systems in Light-Frame Residential Construction Subjected to Natural Hazards, Structures Congress, Nashville, TN, USA, 2004.

[7] B. R. Ellingwood, D. V. Rosowsky, Y. Li, and J. H. Kim, "Fragility assessment of light-frame wood construction subjected to wind and earthquake hazards," Journal of Structural Engineering, vol. 130, no. 12, pp. 1921-1930, 2004.

[8] Y. Li and B. R. Ellingwood, "Framework for multihazard risk assessment and mitigation for wood-frame residential construction," Journal of Structural Engineering, vol. 135, no. 2, pp. 159-168, 2009.

[9] K. H. Lee and D. V. Rosowsky, "Fragility analysis of woodframe buildings considering combined snow and earthquake loading," Structural Safety, vol. 28, no. 3, pp. 289-303, 2006.

[10] J. W. van de Lindt and T. N. Dao, "Performance-based wind engineering for wood-frame buildings," Journal of Structural Engineering, vol. 135, no. 2, pp. 169-177, 2009.

[11] X. Fu, H. N. Li, L. Tian, and J. Wang, "Fragility analysis of transmission line subjected to wind loading," Performance of Constructed Facilities, vol. 33, no. 4, 2019.

[12] M.-A. Asareh, W. Schonberg, and J. Volz, "Fragility analysis of a 5-MW NREL wind turbine considering aero-elastic and seismic interaction using finite element method," Finite Elements in Analysis and Design, vol. 120, no. 1, pp. 57-67, 2016.

[13] N. Usefi and H. Ronagh, "Seismic characteristics of hybrid cold-formed steel wall panels," Structure, vol. 27, pp. 718-731, 2020.

[14] L. A. Fueloep and D. Dubina, "Performance of wall-stud coldformed shear panels under monotonic and cyclic loading Part I: experimental research," Thin-Walled Structures, vol. 42, no. 2, pp. 321-338, 2004.

[15] L. A. Fueloep and D. Dubina, "Performance of wall-stud coldformed shear panels under monotonic and cyclic loading Part II: numerical modelling and performance analysis," ThinWalled Structures, vol. 42, no. 2, pp. 339-349, 2004.

[16] S. Selvaraj and M. Madhavan, "Sheathing bracing requirements for cold-formed steel wall panels: experimental investigation," Structure, vol. 19, pp. 258-276, 2019.

[17] Y. Li, Z. Shen, X. Yao, R. Ma, and F. Liu, "Experimental investigation and design method research on low-rise cold- 
formed thin-walled steel framing buildings," Journal of Structural Engineering, vol. 139, no. 5, pp. 818-836, 2013.

[18] Ministry of Housing and Urban-Rural Development of PR China, Technical Specification for Low-Rise Cold-Formed ThinWalled Steel Buildings, Ministry of Housing and Urban-Rural Development of PR China, Beijing, China, (in Chinese), 2011.

[19] L. Jiang and J. Ye, "Seismic risk assessment of a 2-storey steelsheathed CFS building considering different sources of uncertainty," Structure, vol. 16, pp. 347-357, 2018.

[20] E. Rahmanishamsi, S. Soroushian, and E. M. Maragakis, "Evaluation of the out-of-plane behavior of stud-to-track connections in nonstructural partition walls," Thin-Walled Structures, vol. 103, pp. 211-224, 2016.

[21] R. Retamales, R. Davies, G. Mosqueda, and A. Filiatrault, "Experimental seismic fragility of cold-formed steel framed gypsum partition walls," Journal of Structural Engineering, vol. 139, no. 8, pp. 1285-1293, 2013.

[22] Y. Uematsu and N. Isyumov, "Wind pressures acting on lowrise buildings," Wind Engineering Industrial Aerodynamics, vol. 82, no. 1, pp. 1-25, 1999.

[23] J. D. Ginger, "Characteristics of wind loads on roof cladding and fixings," Wind and Structures, vol. 4, no. 1, pp. 73-84, 2004.

[24] D. Meecham, D. Surry, and A. G. Davenport, "The magnitude and distribution of wind-induced pressures on hip and gable roofs," Wind Engineering Industrial Aerodynamics, vol. 38, no. 2, pp. 257-272, 1991.

[25] P. Huang, L. Tao, M. Gu, and Y. Quan, "Experimental study of wind loads on gable roofs of low-rise buildings with overhangs," Frontiers of Structural and Civil Engineering, vol. 12, no. 3, pp. 300-317, 2018.

[26] P. Huang, L. Tao, M. Gu, and Y. Quan, "Wind effects of architectural details on gable-roofed low-rise buildings in southeastern coast of China," Advances in Structural Engineering, vol. 17, no. 11, pp. 1551-1565, 2014.

[27] Y. Quan, Y. Tamura, and M. Matsui, "Mean wind pressure coefficients on surfaces of gable-roofed low-rise buildings," Advances in Structural Engineering, vol. 10, no. 3, pp. 259-271, 2007.

[28] J. W. van de Lindt, A. Graettinger, R. Gupta, T. Skaggs, S. Pryor, and K. J. Fridley, "Performance of wood-frame structures during hurricane Katrina," Journal of Performance of Constructed Facilities, vol. 21, no. 2, pp. 108-116, 2007.

[29] K. H. Lee and D. V. Rosowsky, "Fragility assessment for roof sheathing failure in high wind regions," Engineering Structures, vol. 27, no. 6, pp. 857-868, 2005.

[30] D. V. Rosowsky and N. Cheng, "Reliability of light-frame roofs in high-wind regions. I: wind loads," Journal of Structural Engineering, vol. 125, no. 7, pp. 725-733, 1999.

[31] D. V. Rosowsky and N. Cheng, "Reliability of light-frame roofs in high-wind regions. II: reliability analysis," Journal of Structural Engineering, vol. 125, no. 7, pp. 734-739, 1999.

[32] M. Hassan, M. R. Ameri, and D. L. J. W. Van, "Wind performance enhancement strategies for residential wood-frame buildings," Performance of Constructed Facilities, vol. 32, no. 3, 2018.

[33] M. Shinozuka, "Basic analysis of structural safety," Journal of Structural Engineering, vol. 109, no. 3, pp. 721-740, 1983.

[34] P. J. Vickery, P. F. Skerlj, J. Lin, L. A. Twisdale, M. A. Young, and F. M. Lavelle, "HAZUS-MH hurricane model methodology. II: damage and loss estimation," Natural Hazards Review, vol. 7, no. 2, pp. 94-103, 2006.

[35] L. A. Fülöp and D. Dubina, "Design criteria for seam and sheeting-to-framing connections of cold-formed steel shear panels," Journal of Structural Engineering, vol. 132, no. 4, pp. 582-590, 2006.

[36] A. G. Davenport, "The spectrum of horizontal gustiness near the ground in high winds," Quarterly Journal of the Royal Meteorological Society, vol. 87, no. 372, pp. 194-211, 1961.

[37] M. Shinozuka and C.-M. Jan, "Digital simulation of random processes and its applications," Journal of Sound and Vibration, vol. 25, no. 1, pp. 111-128, 1972.

[38] Ministry of Housing and Urban-Rural Development of PR China, Load Code for the Design of Building Structures, GB 50009-2012, Ministry of Housing and Urban-Rural Development of PR China, Beijing, China, (in Chinese), 2012.

[39] C. A. Cornell, F. Jalayer, R. O. Hamburger, and D. A. Foutch, "Probabilistic basis for 2000 SAC federal emergency management agency steel moment frame guidelines," Journal of Structural Engineering, vol. 128, no. 4, pp. 526-533, 2002.

[40] Y. Pang, X. Zhou, W. He, J. Zhong, and O. Hui, "Uniform design-based Gaussian process regression for data-driven rapid fragility assessment of bridges," Journal of Structural Engineering, vol. 147, no. 4, Article ID 04021008, 2021.

[41] Y. Pang and X. Wang, "Cloud-IDA-MSA conversion of fragility curves for efficient and high-fidelity resilience assessment," Journal of Structural Engineering, vol. 147, no. 5, Article ID 04021049, 2021.

[42] Ministry of Housing and Urban-Rural Development of PR China, Code for Seismic Design of Buildings, Ministry of Housing and Urban-Rural Development of PR China, Beijing, China, (in Chinese), 2010.

[43] G. L. Zhang, P. G. Wang, M. Zhao, X. DU, and X. Zhao, "Seismic structure-water-sediment-rock interaction model and its application to immersed tunnel analysis under obliquely incident earthquake," Tunnelling and Underground Space Technology, vol. 109, Article ID 103758, 2021.

[44] P. G. Wang, Y. D. Xu, X. L. Zhang, R. Xi, and X. Du, “A substructure method for seismic responses of offshore wind turbine considering nonlinear pile-soil dynamic interaction," Soil Dynamics and Earthquake Engineering, vol. 144, Article ID 106684, 2021.

[45] MBMA 2006, Metal Building Systems Manual, Metal Building Manufacturers Association, Cleveland, OH, USA, 2006.

[46] Ministry of Housing and Urban-Rural Development of PR China, Technical Code of Cold-Formed Thin-wall Steel Structures, GB 50018-2002, Ministry of Housing and Urban-Rural Development of PR China, Beijing, China, (in Chinese), 2010. 